\title{
FATORES DE VARIAÇÃO DOS RESULTADOS DA ANÁLISE QUIMMICA E GRANULOMÉTRICA DE FERTILIZANTES
}

\author{
FERNANDO JOSE PEREIRA DE CAMPOS CARVALHO \\ Engenheiro Agrônomo
}

Orientador: Prof.Dr.Arnaldo Antonio Rodella

Dissertação apresentada à Escola Superior de Agricultura "Luiz de Queiroz", da Universidade de são Paulo, para a obtenção do titulo de Mestre em Agronomia, Area de Concentração: Solos e Nutrição de Plantas

PIRACICABA

Estado de São Paulo - Brasil

Fevereiro - 1995 
Ficha catalográfica preparada pela seção de Livros da Divisão de Biblioteca e Documentação - PCLQ/USP

Carvalho, Fernando José Pereira de Campos

C331f Fatores de variação dos resultados da análise quımı ca e granulométrica de fertilizantes. Piracicaba, 1995.

90p. ilus.

Diss. (Mestre) - EsALQ

Bibliografia.

1. Adubo - Análise química 2. Adubo - Granulometria I. Escola superior de Agricultura Luiz de Queiroz, Pira cicaba

CDD 631.8 


\title{
FATORES DE VARIACÃ̃O DOS RESULTADOS DA ANÁLISE QUIMMICA E GRANULOMÉTRICA DE FERTILIZANTES
}

FERNANDO JOSE PEREIRA DE CAMPOS CARVALHO

\begin{abstract}
Aprovado: $25 / 04 / 95$
Comissão Julgadora:

Prof. Dr. Arnaldo Antonio Rodella ESALQ/USP

Prof. Dr. José Carlos Alcarde $\quad--\quad$ ESALQ/USP

Prof. Dr. Luis Carlos Ferreira da Silva CCA/UFSCAR
\end{abstract}

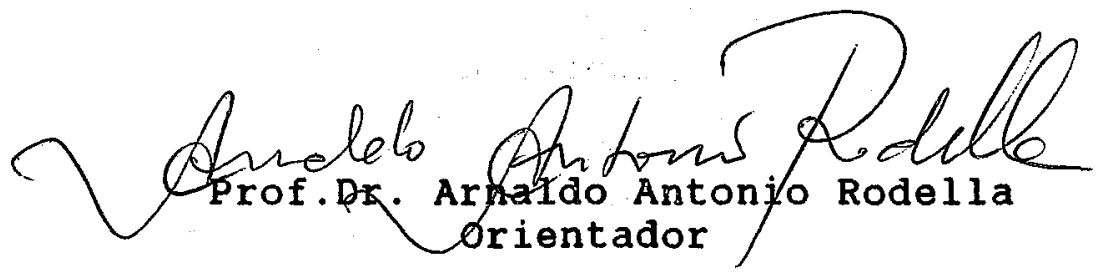


Aos meus pais,

Paulo e Sylvia,

pelo incentivo

OFEREÇO

A Roseli, minha esposa

meus filhos Fernando,

Renata e o que virá

pelo apoio incondicional

DEDICO 
AGRADECIMENTOS

A Deus por mais esta etapa.

Ao Ministério da Agricultura, do Abastecimento e Reforma Agrária, através do Serviço de Produção Vegetal/DFAARA/SP e a Escola Superior de Agricultura "Luiz de Queiroz"/USP, através do Departamento. de Química, pela oportunidade da realização do curso de Pós-Graduação.

A CAPES, pela concessão de Bolsa de Estudos.

A TAKENAKA S.A. pela execução das determinaçōes analíticas.

Ao Professor Dr. Arnaldo Antonio Rodella, pelos ensinamentos, amizade e dedicação como orientador do trabalho.

Ao professor Dr. José Carlos Alcarde, pela co-orientação e conhecimentos transmitidos em todas as fases do trabalho.

Ao professores Dr. Décio Barbin, pelo auxilio nas análises estatisticas.

Aos Professores do Curso de Pós Graduação em Solos e Nutrição de Plantas, pelos ensinamentos.

Aos Engenheiros Agrônomos e Químicos Vinicio Angellicci, Marina Hashiguchi, Marcelo Laurino, Frederico Pinheiro, pelas sugestōes, incentivo e amizade.

Aos funcionários e técnicos do Setor de Química Analítica do Departamento de Química da ESALQ, em especial Rita de Cássia Castro e Maria Angélica Bernardino, pelas facilidades e colaboração prestada na condução do trabalho.

As bibliotecárias Katia Maria Ferraz, Eliana Maria Sabino, pela revisão das referências bibliográficas.

A todas as pessoas que auxiliaram direta e indiretamente a execução do trabalho. 
SUMARIO

página

LISTA DE FIGURAS...................... vii

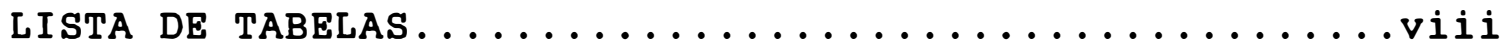

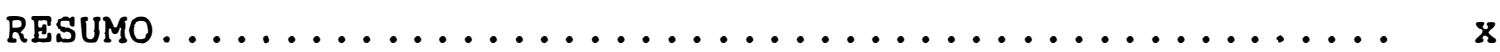

SUMMARY .................................

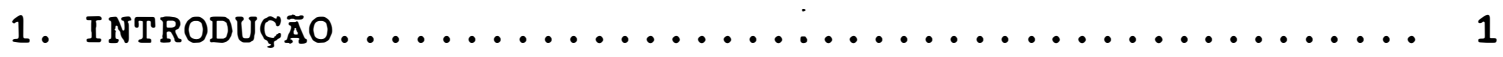

2. REVISÃO BIBLIOGRAFICA.................... 5

2.1. Produção e consumo de fertilizantes no Brasil... 5

2.2. Consideraçōes sobre mistura de fertilizantes.... 7

2.2.1. Compatibilidade, higroscopicidade e

empedramento.................. 8

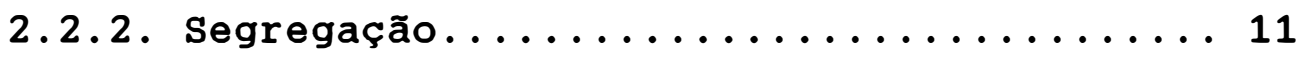

2.3. Controle de qualidade.................. 14

2.3.1. Amostragem e redução da amostra........ 15

2.3.2. Determinaçỏes analiticas............ 17

2.3.3. Programas interlaboratoriais.......... 18

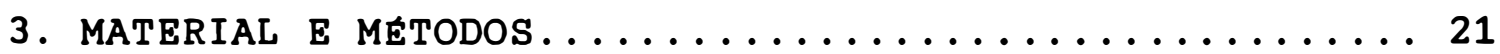

3.1. Contribuição das diversas etapas da análise

de fertilizantes para a variabilidade dos

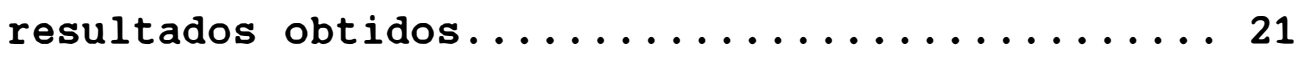

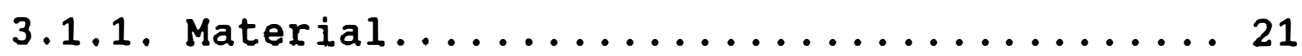

3.1.2. Etapas realizadas no campo........... 21

3.1.2.1. Local da amostragem.......... 21

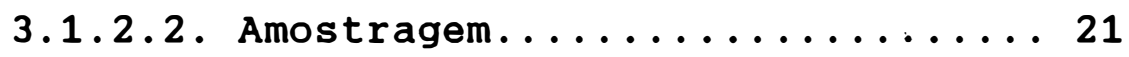

3.1.2.3. Redução da amostra.......... 23

3.1.3. Etapas realizadas no laboratório....... 25

3.1.3.1. Análise granulométrica....... 25

3.1.3.2. Análises químicas.......... 25

3.1.4. Análise estatística.............. 28

3.1.4.1. Variabilidade nos resultados de análise química: determinaçōes de nitrogênio, fósforo e potássio............... 28 
3.1.4.2. Distribuição das massas de fertilizantes no processo de quarteação............... 29

3.1.4.3. Variabilidade nos resultados de análise granulométrica...... 31

3.2. Estudo interlaboratorial: variabilidade dos teores de nitrogênio, fósforo e potássio em função do método e do laboratório........... 32

3.2.1. Laboratórios participantes........... 32

3.2.2. Material utilizado................ 33

3.2.2.1. Fertilizantes minerais simples.. 33

3.2.2.2. Fertilizantes minerais mistos... 34

3.2.3. Preparo das amostras.............. 34

3.2.4. Determinações analíticas........... 35

3.2.4.1. Nitrogênio............. 36

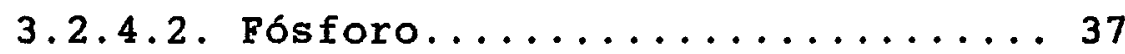

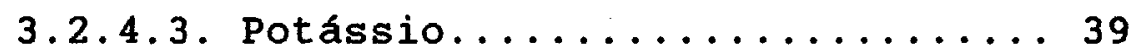

3.2.5. Análise estatística.............440

3.2.5.1. Análise estatística básica..... 40

3.2.5.2. Desempenho dos laboratorios.... 40

3.2.5.3. Comparação entre métodos analiticos................4 41

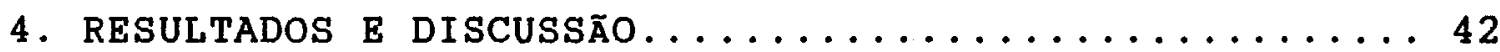

4.1. Contribuição das diversas etapas da análise de fertilizantes para a variabilidade dos resultados obtidos...................442

4.1.1. Distribuição das massas de fertilizante no processo de quarteação..........4 42

4.1.2. Análise granulométrica.............44 44

4.1.2.1. Caracterização da mistura de grânulos estudada...........444

4.1.2.2. Variabilidade dos resultados de análise granulométrica.....44 47

4.1.3. Variabilidade nos resultados de análise quimica: determinaçōes de nitrogênio, fósforo e potássio...........4 47

4.1.3.1. Determinação de nitrogênio..... 48 4.1.3.2. Determinação de fósforo.......4 49 4.1.3.3. Determinação de potássio.......49 49 
4.2. Variabilidade na determinação de nitrogênio, fósforo e potássio em função dos laboratórios e dos método analiticos............... 52 4.2.1. Determinação de nitrogênio total....... 52 4.2.2. Determinação de fósforo........... 54 4.2.3. Determinação de potássio........... 57

5. Conclusões......................... 60

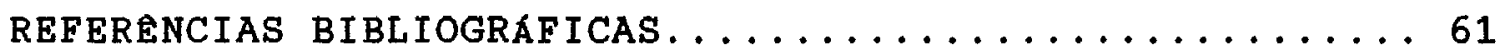


LISTA DE FIGURAS

Figura 1. Quadro de compatibilidade química de fertilizantes (adaptado de HOFFMEISTER, 1973)......99

Figura 2. Esquema da sonda oficial para a amostragem de produtos ensacados e procedimento de coleta de fertilizantes ensacados (BRASIL,

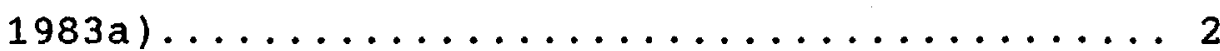

Figura 3. Representação esquemática do quarteador "tipo Jones". (BRASIL, 1983a)............ 24

Figura 4. Esquema das etapas envolvidas no processo de amostragem e determinaçōes realizadas no

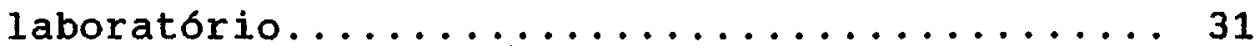

Figura 5. Misturador de fertilizantes idealizado por

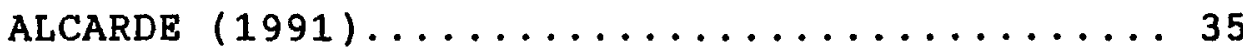

Figura 6. Relação entre teores de nitrogênio total em fertilizantes determinados pelos métodos oficiais da liga de Raney e do ácido salicílico e pelo método simplificado..........54

Figura 7. Relação entre teores de fósforo total, fósforo solúvel em água e fósforo solúvel em solução neutra de citrato de amônio mais água, determinados pelos respectivos métodos oficiais e simplificados........... 56

Figura 8. Relação entre teores de potássio em fertilizantes determinados pelos métodos of $i$ ciais, fotométrico de chama e tetrafenilborato de sódio (TFBS), e método fotométrico de chama simplificado.................59 
viii

\section{LISTA DE TABELAS}

Tabela 01 . Dados relativos aos fertilizantes entregues ao consumidor final nos anos de 1986 a 1993, em milhares de toneladas...........6 6

Tabela 02 . Número mínimo de sacos a serem amostrados conforme o tamanho do lote.(BRASIL, 1983a)... 23

Tabela 03. Quadro de análise de variância dos resultados de análise química no modelo de classificação hierárquica............. 29

Tabela 04. Quadro de análise de variância das massas obtidas na redução da amostra no modelo de classificação hierárquica............. 30

Tabela 05. Quadro de análise de variância dos resultados da análise granulométrica..........32

Tabela 06. Frequência de remessa e relação dos fertilizantes simples enviados para análise no programa interlaboratorial.............33

Tabela 07 . Número de amostras de fertilizantes minerais mistos estudadas em cada intervalo de concentração de nutrientes.............34

Tabela 08. Composição de variância das massas de amostras de fertilizantes obtidas no processo de amostragem................43

Tabela 09. Imagens, porcentagens da massa total e resultados de análise químicas, das diferentes fraçoes granulométricas em que foi fracionada a mistura de fertilizantes 4-14-8 estudada...................446 
Tabela 10. Efeito da amostragem e quarteação no campo sobre a precisão dos resultados da análise granulométrica.................. 47

Tabela 11. Composição da variância do resultado da análise de fertilizante para a determinação de nitrogênio total...............448

Tabela 12. Composição da variância do resultado da análise de fertilizante para a determinação de fósforo solúvel em CNAtágua.........4 49

Tabela 13. Composição da variância do resultado da análise de fertilizante para a determinação de potássio.................... 50

Tabela 14. Comparação entre laboratórios na determinação de nitrogênio total pelos métodos oficiais da liga de Raney e do ácido salicílico e método simplificado............ 53

Tabela 15. Comparação entre laboratórios na determinação de fósforo total, solúvel em água e solúvel em solução neutra de citrato de amônio mais água (CNA + água).......... 55

Tabela 16. Comparação entre laboratórios na determinação de potássio pelo método oficial do tetrafenilborato de sódio (TFBS) e método fotométrico de chama, nas versōes oficial e simplificada................... 58 
FATORES DE VARIAÇÃO DOS RESULTADOS DA ANALISE QUIMICA E GRANULOMETRICA DE FERTILIZANTES

\section{Autor: FERNANDO JOSE PEREIRA DE CAMPOS CARVALHO Orientador: Prof.Dr. ARNALDO ANTONIO RODELLA}

RESUMO

Considerou-se a variação nos resultados de análise de fertilizantes, em função das etapas que compōe a marcha geral da análise desse material, ou seja: coleta de amostra, redução da quantidade amostrada por meio de quarteação, no campo e em laboratório, e a determinação analitica. Nesse sentido, estudou-se assim a determinação dos teores de nitrogênio, fósforo e potássio, e também das fraçōes granulométricas, de uma mistura de grânulos de fórmula 4-14-8, através do modelo estatístico de classificação hierárquica. Com relação à determinação analitica, o estudo baseou-se num programa interlaboratorial de análises químicas da rede de laboratórios oficiais do Ministério da Agricultura, através dos resultados de determinações de nitrogênio, fósforo e potássio, em fertilizantes simples e mistos, nas metodologias oficial e simplificada.

Na análise granulométrica foram encontrados efeitos significativos da amostragem e quarteação, na determinação das frações extremas de diâmetrọ (> 4,00mm e < 1,19 $\mathrm{mm})$. Cerca de 448 da variância da distribuição de massa das amostras pôde ser relacionada à coleta pela sonda, 49,88 à quarteação de campo e 6,28 à quarteação de laboratório. Da variância total dos resultados das determinações de nutrientes $24,98,71,58$ e 7,08 foram atribuidos a etapa da amostragem nas determinaçōes de nitrogênio, fósforo e potássio, respectivamente. Ainda nessa mesma sequência de elementos, a quarteação no campo participou com 4,58, 2,58 e 42,08, en- 
quanto que para a quarteação no laboratório os valores das proporções foram 25,58, 4,78 e 13,78. A determinação analítica correspondeu a 45,18 da variância do teor de nitrogênio; valores de $21,3 \%$ e $37,3 \%$ foram encontrados para as determinações de fósforo e potássio, respectivamente. Os resultados obtidos evidenciaram que através do modelo de classificação hierárquica foi possivel estabelecer a contribuição relativa das etapas do processo de análise na variância dos resultados de distribuição de massa e análises químicas. A variabilidade relativamente pequena observada nos resultados das amostras compostas foi devido ao número elevado de amostras simples que as compõem.

Com relação aos resultados do estudo interlaboratorial, diferenças estatisticamente significativas entre laboratórios foram encontradas na determinação de fósforo solúvel em solução neutra de citrato de amônio mais água pelos métodos oficial e simplificado. Já para fósforo total e fósforo solúvel em água, diferenças significativas foram observadas apenas no método simplificado, o que não ocorreu em nenhuma situação para as determinaçōes de nitrogênio e potássio. Na comparação entre métodos analíticos empregando a regressão linear não foram encontradas diferenças significativas ao nível de 58 de probabilidade. 
FACTORS OF VARIANCE IN THE RESULTS OF CHEMICAL AND GRANULOMETRIC ANALYSES OF FERTILIZER

\author{
Author: FERNANDO JOSE PEREIRA DE CAMPOS CARVALHO \\ Adviser: Prof.Dr. ARNALDO ANTONIO RODELLA
}

SUMMARY

The variance in the results of fertilizer analyses was studied on the basis of the steps of the analytical procedure: sampling, reduction of the collected sample by quartering, in the field and in the laboratory, and the analytical determinations. The fertilizer material used in this study was a blend of granules formulated in the 4-14-8 proportions, which was determined for nitrogen, phosphorus and potassium, as well for the granulometric fractions. The statistical model was the hierarchical classification. The database of the study was the results of the analytical determinations of an interlaboratory program of the Ministry of Agriculture. The results of nitrogen, phosphorus and potassium determinations were studied in simple and blended fertilizers, according to the official and simplified methodology.

In the granulometric analysis, significant effects of sampling and quartering were found in the determinations of frations the extreme diameter (>4.00mm and $(1.19 \mathrm{~mm})$. About 448 of the variance of the sample mass distribution could be related to the sampling with the probe, 49.88 to the field quartering and 6.28 to laboratory quartering. The proportions of the total variance for the nutrient determinations were: $24.98,71.58$ and 7.08 for nitrogen, phosphorus and potassium, respectively, in the sampling; in the same sequence the elements were $4.58,2.58$ 
and 42.08 in the field quartering and $25.58,4.78$ and 13.78 in the laboratory quartering. The chemical determination accounted for 45.18 of the variance for nitrogen, 21.38 for phosphorus and $37.3 \%$ for potassium. Thus, it was possible through the model of hierarchical classification to establish the relative contribution of the steps of the analytical procedure on the variance of the results of mass distribution and chemical determinations. The relatively small variability observed in the results of composite samples was attributed to the large number of simple samples involved.

The results of the interlaboratory study indicated significant differences among laboratories in the determination of phosphorus soluble in aqueous neutral solution of amonium citrate with both the official and simplified methods. For total phosphorus and water soluble phosphorus significant differences were noted only in the simplified method. There were no differences for nitrogen and potassium determinations neither for the simplified nor the official methods. Using linear regression to compare the analytical methods no relevant differences were found at 58 probability level. 
1. INTRODUÇ $\tilde{A} O$

Diferentes fatores atuam sobre o sistema fisiológico da planta, de modo a influir no seu desenvolvimento: temperatura, disponibilidade de água e de nutrientes, cultivar empregado, operações agricolas efetuadas, entre outros. Quando se explora comercialmente uma determinada cultura, a obtenção da produtividade desejada exige a análise da influência dos fatores citados anteriormente. Alguns deles não podem ser controlados, como a temperatura, mas outros, como o suprimento de nutrientes, pode ser complementado pela utilização de fertilizantes.

A adubação racional e eficiente ocupa lugar de destaque, tanto em termos quantitativos, no sentido de aumentar a produtividade, como na melhoria da qualidade dos produtos agricolas. Pode ser imprescindivel, como na expansão da agricultura para solos de baixa fertilidade, aqueles sob vegetąão de cerrado por exemplo, nos quais muitas vezes a exploração agrícola somente é viabilizada do ponto de vista econômico através do uso correto de fertilizantes, bem como de corretivos. Apesar disso, no Brasil, pode-se considerar que apenas recentemente a utilizaça de adubos minerais teve maior impulso, quando, a partir dos anos 70 foi implantado o PNFCA-Programa Nacional de Fertilizantes e Calcário Agricola.

Devido à importância que os fertilizantes têm como fator de produtividade, bem como pela significancia da participação desse insumo nos custos produção, torna-se imperativo a avaliaço das várias caracteristicas e dos fatores responsáveis pelo seu desempenho, a fim de se maximizar a 
eficiência desse insumo. Nesse sentido, destaca-se de início, o perfeito conhecimento da composição química do produto para - suprimento adequado das necessidades nutricionais das culturas.

Os fertilizantes minerais podem ser veiculados sob diferentes formas: granulados, misturas granuladas, misturas de grânulos, pó farelados, bem como misturas fluidas. Devido ao menor custo, a produção e a comercialização das misturas de grânulos tem aumentado, mas a elaboração desse produto apresenta dificuldades para se obter uniformidade exigida na sua composição.

A segregação dos componentes, comumente observada nas misturas de grânulos, provoca variaçōes nos teores de nutrientes, além de provocar problemas na aplicação de doses corretas no campo, dificulta a obtenção de amostras representativas, exigidas para o perfeito controle de qualidade do fertilizante.

Do ponto de vista industrial, o controle de qualidade de um produto pode ser entendido como um conjunto de atividades que tem por objetivo a obtenção de um produto que satisfaça determinados padrões pré-fixados, normalmente em função das exigências do mercado. Por outro lado, à nível de consumo, têm-se o controle de qualidade desenvolvido pelos orgãos governamentais, no Brasil o Ministério da Agricultura, ou pelo próprio consumidor, com a finalidade de avaliar se as especificações garantidas pelo produtor são efetivamente observadas no produto comercializado.

Enquanto que no primeiro caso o controle de qualidade deve ser realizado em todas as etapas do processo de produçăo, no segundo a quantidade de nutrientes garantida na embalagem é comprovada através de análise química de amostra retirada da embalagem do produto, ou das quantidades veiculadas a granel. 
4

o controle de qualidade de fertilizantes, efetuado para fins de fiscalização, corresponde essencialmente à sua análise química. o processo se inicia pela coleta de amostras no local de produção, armazenamento ou utilização do produto e se completa no laboratorio de análises.

A obtenção de uma amostra estatisticamente representativa requer a manipulação de um número relativamente grande de sacos. Como, em geral, a quantidade de produto necessário para as determinaçōes analíticas é muito pequena em relação à quantidade amostrada, torna-se necessário reduzir tanto a amostra coletada no campo como também a subamostra enviada ao laboratorio. Nota-se assim, que a qualidade do resultado final da análise química depende de uma série de operaçōes que antecedem à determinação analitica dos constituintes de interesse no laboratório de análise.

o êxito no controle de qualidade de fertilizante depende fundamentalmente da correta condução do procedimento de análise química. Pode ocorrer conflito de interesses quando o teor garantido pelo produtor não concorda com os teores determinados na análise química efetuada por iniciativa do consumidor. E evidente que a complexidade do processo tem de ser levada em conta, extrapolando o simples questionamento da determinação analitica como frequentemente ocorre. o parâmetro estatístico variância do teor de nutriente determinado no fertilizante, é constituida pela soma das contribuiçoes das diferentes etapas conduzidas.

o objetivo do presente trabalho foi a avaliação de alguns fatores que contribuem para a variabilidade dos resultados da análise de fertilizantes e para tanto foram desenvolvidos dois tipos de estudo. No primeiro, procurou-se estabelecer a contribuicão das diferentes etapas da análise química de uma mistura de grânulos, na variância do resultado final, obtidos em um único laboratório. No segundo, objeti- 
vou-se avaliar o comportamento de diferentes laboratórios e métodos analíticos na determinação dos teores de nutrientes de diferentes tipos de fertilizantes. 
2. REVISÃO BIBLIOGRAFICA

2.1. Produção e consumo de fertilizantes no Brasil

Segundo dados apresentados pela Associação Nacional para Difusão de Adubos e Corretivos Agrícolas - ANDA (ANDA, 1986-1993), no período de 1970 a 1993, a aplicação de fertilizantes na agricultura brasileira aumentou de 25 para $72 \mathrm{~kg}$ por hectare cultivado, promovendo aumento de 1.437 $\mathrm{kg} / \mathrm{ha}$ na produtividade das 16 principais culturas exploradas no Brasil.

Os dados disponíveis sobre o consumo de fertilizantes no Brasil permitem que se elabore um panorama referente ao período de 1986 a 1993. Na Tabela 1, são apresentadas as quantidades de fertilizantes entregues ao consumidor final, no intervalo citado (ANDA, 1986-1993).

De maneira geral, o exame da Tabela 1 revela que o consumo total de fertilizante está claramente relacionado às variações da situação econômica do país, bem como aspectos especificos do setor agricola: crédito rural e preço mínimo dos produtos agricolas. De 1989 a 1991, registraramse os mais baixos valores de consumo de fertilizantes, refletindo os problemas de altos indices de inflação e escassez de recursos para financiamento. A partir de 1992, nota-se a elevacão do consumo, sendo que em 1993 ultrapassa-se os valores observados em 1988.

De acordo com FERREIRA (1993), a previsão do consumo nacional de fertilizantes em 1993 era de 10 milhões de toneladas contra 9,277 milhões consumidos em 1992. Os 
principais fatores que contribuiram para este aumento foram - aumento do consumo de fertilizantes em diversas culturas, principalmente a soja, e a definição da politica agricola para a safra $1993 / 1994$.

Tabela 1. Fertilizantes entregues ao consumidor final nos anos de 1986 a 1994 em milhare de toneladas.

\begin{tabular}{|c|c|c|c|c|c|c|}
\hline \multirow[t]{2}{*}{ ano } & \multicolumn{3}{|c|}{ formulações $N-P-K$} & \multirow{2}{*}{$\begin{array}{l}\text { mineral } \\
\text { simples }\end{array}$} & \multirow[t]{2}{*}{ total } & \multirow{2}{*}{ fórm. média } \\
\hline & granulado & pó & m.grân". & & & \\
\hline 1986 & 2092,36 & 479,92 & 4637,47 & 1960,57 & 9170,57 & $9-16-13$ \\
\hline 1987 & 1837,14 & 478,84 & 5192,15 & 2137,42 & 9645,54 & $9-16-14$ \\
\hline 1988 & 2389,58 & 393,40 & 4690,01 & 2292,40 & 9765,39 & $8-15-14$ \\
\hline 1989 & 2050,28 & 419,24 & 4320,26 & 1969,07 & 8758,85 & $9-15-14$ \\
\hline 1990 & 1419,89 & 546,70 & 4504,05 & 1751,84 & 8222,47 & $9-14-14$ \\
\hline 1991 & 1464,34 & 613,82 & 4504,25 & 1910,56 & 8492,97 & $9-14-14$ \\
\hline 1992 & 1572,21 & 581,28 & 5105,35 & 2015,62 & 9277,46 & $9-15-15$ \\
\hline 1993 & 1643,23 & 739,33 & 5733,35 & 2425,42 & 10541,33 & $10-15-15$ \\
\hline média & 1808,63 & 531,57 & 4835,86 & 2057,86 & 9233,92 & $9-15-14$ \\
\hline 8 & 19,59 & 5,76 & 52,37 & 22,28 & 100,00 & $9-15-14$ \\
\hline
\end{tabular}

m.grân.* = mistura de grânulos

Segundo o mesmo autor, a entrega de fertilizantes em 1993, superou a previsão em 541.000 toneladas, representando um incremento de 13,638 ou 1,264 milhões de toneladas no consumo nacional de fertilizantes em relacão a 1992. Já a previsão para o ano de 1994, que era de 11 milhões de toneladas, pode ser até maior considerando-se que entre janeiro e setembro foram entregues 7,718 milhoes de toneladas, representando um incremento de 5,28 em relação ao mesmo período de 1993. (FERREIRA, 1994).

A Tabela 1 mostra também que 52,378 dos fertilizantes consumidos no Brasil, foram na forma de misturas de grânulos, o que equivale a 67,388 do consumo de fertilizantes formulados. 
2.2. Considerações sobre mistura de fertilizantes

A necessidade de aplicação conjunta de nutrientes, em diversas proporçoes adequadas aos diversos solos e culturas, levou os fabricantes a produzirem misturas de fertilizantes contendo os nutrientes nitrogênio, fósforo $\theta$ potássio, denominadas fórmulas NPK. Quando nessas formulaçōes, os nutrientes estão reunidos em um mesmo grânulo, têm-se uma mistura complexa (granulado) ou uma mistura granulada. Quando cada grânulo corresponde a um fertilizante simples, obtém-se uma mistura de grânulos.

A mistura de grânulos foi muito difundida, pois, sendo tecnologicamente mais simples de preparar, e assim mais barata, ainda permitia obter rapidamente um número ilimitado de fórmulas. Contudo, em vista da diversidade na procedência das matérias primas, com granulometria variável, a mistura obtida possuía sérios problemas de qualidade, como por exemplo, segregacão, empedramento, higroscopicidade. Visando minimizar esses problemas, com o tempo, os fertilizantes simples passaram a ser granulados de tal forma que as misturas dos grânulos NPK tivessem melhor qualidade (SILVEIRA, 1990).

Segundo KUMMER (1989), a recomendação de aplicacão de fertilizantes de acordo a análise do solo e considerando as caracteristicas da cultura, é o método ideal. Esta situação porém, pode exigir uma grande varie-dade de formulaçoses e neste caso, pela sua versatilidade de produção, as misturas de grânulos apresentam vantagem em relação ao produtos granulados. Na prática, entretanto, essa vantagem é minimizada, já que a diferença de granulometria das particulas não permite uniformidade de aplica- çã, e melhores resultados podem ser obtidos com fertilizantes granulados. 
Ainda segundo KUMMER (1989), o uso de mistura de grânulos nos EUA é mais difundido nas culturas onde pequenas variações na aplicação de doses de nutrientes não afetam a produção ou qualidade do produto, citando como exemplo o milho, a soja e as forrageiras. Já para culturas onde a qualidade varia sensivelmente com a dosagem dos nutrientes, como - fumo, as frutas e hortalicas, a maior parte da lavouras são fertilizadas com misturas granuladas.

Comparando diversos tipos de fertilizantes, misturas de grânulos, misturas granuladas e complexos do mundo inteiro, POPP \& ULLRICH (1985b) concluíram que tanto as misturas de grânulos como as misturas granuladas não atingiam - nível de qualidade esperado, ao contrátio do que ocorria com os fertilizantes complexos, tanto nas características fisicas como granulometria, dureza, abrasividade e fluidez, como em relação aos teores de nutrientes declarados.

Segundo MALAVOLTA (1981), quando a mistura de fertilizantes é mal preparada, não obedecendo às regras de compatibilidade fisica e química, o produto apresenta problemas de perdas de nutrientes, segregação e empedramento. Assim, deve-se evitar a utilização simultânea de matérias primas incompativeis que diminuam a qualidade do produto final.

2.2.1. Compatibilidade, higroscopicidade e empedramento

Conforme salientado por MALAVOLTA (1981), quando diferentes fertilizantes são reunidos simultaneamente em uma mesma mistura, a interacão entre eles pode ocorrer sequndo diversos niveis:

compatibilidade total: os fertilizantes podem ser misturados em qualquer proporcão; 
compatibilidade limitada: a mistura de dois fertilizantes só pode ser feita em determinadas proporções; incompatibilidade: a mistura é impossível sem que haja prejuizo irreversível da qualidade do produto final. As possibilidades de preparo de misturas à partir dos principais fertilizantes simples são mostradas na Figura 1.

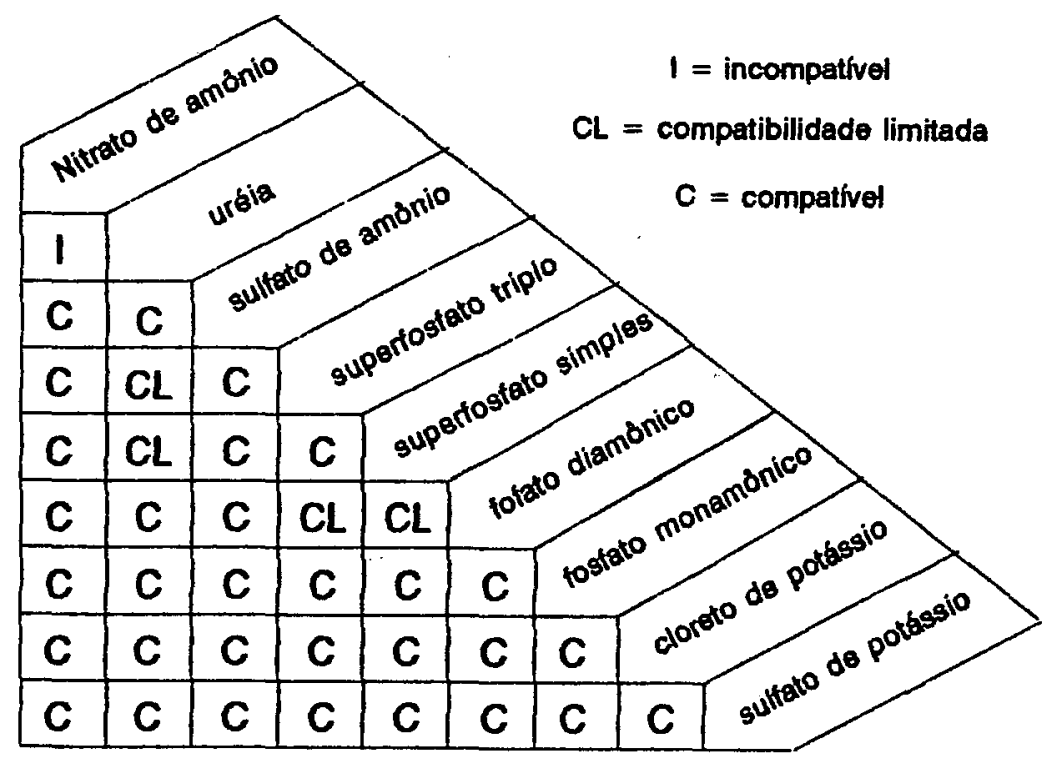

Fiqura 1. Quadro de compatibilidade química de fertilizantes (adaptado de HOFFMEISTER, 1973).

Nota-se que a uréia não pode ser misturada com - nitrato de amônio, enquanto que com o superfosfato tanto simples como triplo a compatibilidade é limitada. Pode-se cheqar à incompatibilidade total, dependendo do conteúdo de áqua do superfosfato. O que causa esta incompatibilidade é a reação química que ocorre entre a uréia e o fosfato monocálcico monoidratado, o principal constituinte dos superfosfatos, a qual causa a aderência do fertilizante nos equipamen- 
tos. Já a compatibilidade limitada da mistura entre os superfosfatos e o fosfato diamônico foi estabelecida à partir de experimentos de armazenamento, onde ocorreram reações que causaram o empedramento da mistura. (HOFFEMEISTER, 1975).

As caracteristicas de qualidade dos fertilizantes, segundo ALCARDE et alli (1991) e ALCARDE (1992), são as condições naturais ou artificiais que esses produtos podem apresentar e tem relação direta ou indireta com a sua eficiência. Diferentes características são consideradas e podem ser de natureza física: estado físico, granulometria, consistência, fluidez, densidade; natureza química: número, forma química e teor de nutrientes, e presença de compo- nentes nocivos aos vegetais; ou de natureza físico-química: solubilidade, higroscopicidade, índice salino e empedramento.

Ainda, segundo esses autores, higroscopicidade é a tendência que os materiais apresentam de absorver umidade do ar atmosférico. Para cada fertilizante simples ou mistura, há um máximo de umidade relativa do ambiente ou umidade relativa critica (UCR), a que o produto pode ser exposto sem absorver umidade.

o produto resultante da mistura de dois fertilizantes simples normalmente apresenta uma menor UCR, ou seja, maior higroscopicidade que os constituintes isolados. Se a umidade relativa do ar for maior que a UCR da mistura, ocorrerá hidratação das partículas, depois quebra, reação química e formaça de pontes de cristais das particulas causando o empedramento. o exemplo de um caso extremo é o da mistura de uréia e nitrato de amônio, que apresentam respectivamente valores de UCR de 72,58 e 59,48 e quando misturados - valor da UCR abaixa para 188, demostrando que a mistura destes dois sais fertilizantes proporcionará um produto final de má qualidade, sendo esta uma das razōes porque esta mistura é considerada incompatível na Figura 1. 
Numerosos são os inconvenientes de um fertilizante úmido ou que apresente forte tendência para tal: queda no teor de nutrientes, dificuldade de manuseio e distribuicão, aderência nos acondicionadores, além de ser o principal responsável pelo empedramento dos fertilizantes. (SILVERBERG et alli, 1958; HOFFMEISTER, 1979).

Segundo ALCARDE (1992), visando aumentar a resistência à higroscopicidade e empedramento dos fertilizantes, os produtores aumentaram o tamanho das partículas e utilizaram aditivos para o revestimento dos grânulos, principalmente para produtos com alto teor de nitrogênio como a uréia e o nitrato de amônio.

Para HOFFMEISTER (1979), com a utilização de sacos plásticos como embalagem das misturas, o efeito da umidade relativa do ar é diminuido. Nestas situações, o empedramento que ocorrer será devido a outras causas como a natureza dos constituintes da mistura, reações químicas entre eles, temperatura e pressão no armazenamento e presença de partículas menores que $0,3 \mathrm{~mm}$, entre outros.

\subsubsection{Segregação}

Segundo HOFFMEISTER (1962) e MALAVOLTA (1981), a seqreqaça pode ser definida como a separaça física dos grânulos e constitui a causa principal de falta de uniformidade em algumas misturas de grånulos inadequadamente preparadas. A falta de uniformidade pode fazer com que a amostra retirada de uma mistura para análise não seja representativa, não corresponda à garantia e também pode causar uma distribuicão desigual no campo, acarretando crescimento e produção irregulares das plantas.

A desuniformidade do tamanho das particulas $e$ o fator que mais favorece a segregaçao, a qual ocorre não so 
durante o processo de produção, mas continua no transporte, armazenamento, distribuição, bem como na amostragem e redução da amostra para análise química. A segregação, pode afetar significativamente o resultado da análise química dificultando a verificação dos teores garantidos. Se o produto for granulado e todas as particulas possuirem a mesma constituição química o problema da segregação é minimizado, enquanto que se o produto for uma mistura de grânulos a segregaça é um problema sério, principalmente se existirem particulas menores que $0,3 \mathrm{~mm}$. (HOFFMEISTER et alli, 1964 e HOFFEMEISTER, 1973; MALAVOLTA, 1978; RODELLA \& ALCARDE, 1994; PRESSINOTTI, $1984)$.

O efeito da segregação sobre a composiç̃o do fertilizante pode ser acentuado, quando a pedido de um agricultor, são adicionados micronutrientes em pequenas doses, normalmente na forma de pó, para constituir a mistura de grânulos. (SILVERBERG et alli, 1972).

HOFFMEISTER et alli (1964), comentam que o efeito da densidade e a forma das partículas na segregação das misturas de grânulos, é muito pequeno e insignificante quando comparado com o efeito que causa uma pequena variaçao no tamanho das particulas.

Estudos realizados por SMITH (1961), indicaram que para diversas misturas transportadas por trens, caminhões e outros meios, não ocorreu a segregação das partículas na maioria das misturas transportadas por $48 \mathrm{~km}$.

$$
\text { POPP \& ULLRICH (1985a), testando a aplicação }
$$

dos fertilizantes em diversos tipos de adubadora observaram que os equipamentos que utilizam forca centrifuga, não são recomendados para a aplicacão de misturas de grânulos. Os outros tipos como os dosadores volumétricos podem dar bons resultados, desde que o produto não tenha segregado durante - transporte e armazenamento. Já para os produtos granulados 
a adubadora centrifuga se comportou muito bem, sendo maior a eficiência se o produto possuir grânulos entre 1,5 e $4,5 \mathrm{~mm}$. No mercado nacional, segundo BALASTREIRE \& COELHO (1992), tanto para a aplicação à lanço ou em linha, predominam as adubadoras com mecanismo dosadores volumetricos, dos quais os mais comuns são: rotores dentados horizontais, roscas-sem-fim e prato giratório.

o modo efetivo de diminuir o problema da segregação é a utilização de ingredientes de granulometria similar, empregando-se como critério a diferença máxima de $10 \%$ entre as curvas de distribuicão granulométricas. Nem sempre isto é possivel devido a diferença entre os diversos fertilizantes simples. Muitas vezes, cuidados na preparaça da mistura, também diminuem a segregação. (HOFFMEISTER, 1976)

Sequndo GOSSELIN (1983), a cooperação entre os produtores de fertilizantes simples com os produtores de misturas é uma prática efetiva na melhoria das misturas. Como exemplo cita o sistema de identificação dos materiais SGN do Instituto de Fertilizantes do Canadá, que classifica os fertilizantes simples por um número que representa o diametro médio das partículas multiplicado por 100. Este sistema foi implantado em 1982, sendo utilizado por empresas produtoras de potássio, nitrogênio e fósforo do Canadá. Segundo alguns produtores de mistura, o resultado desse esforco foi a diminuição do número de amostra deficientes, em análises oficiais. Outra maneira de aumentar a qualidade das misturas, segundo TERRY (1983) e ROGERS (1983) é melhorar as condiçoses de fabricação, fixando normas de limpeza, produção e controle de qualidade, tanto das matérias primas como das misturas. Para isso recomenda-se analisar periodicamente as fórmulas mais vendidas, determinando a média, o desvio padrão e o coeficiente de variação dos resultados. 
Sequndo esses mesmos autores, uma maior periodicidade do controle de qualidade por parte dos órgãos oficiais também melhora a qualidade dos produtos. Estimaram que, se forem amostrados de 10 a $15 \%$ do fertilizante produzido, a qualidade das misturas melhorarão bastante.

Para WATLEY (1978), a eficiência do controle de qualidade na fabricacão do fertilizante pode ser avaliada comparando o resultado das amostras oficiais de fiscalização com a garantia do produto, sem considerar a tolerância da legislação.

\subsection{Controle de qualidade}

Embora a qualidade dos fertilizantes sólidos possa ser avaliada considerando diferentes características de qualidade físicas, químicas e físico-químicas, na legislação somente a qranulometria e o teor de nutriente são fatores cuja avaliação é prevista para fins de fiscalização. Atualmente, como a análise granulométrica não tem sido efetuada, - controle de qualidade se confunde com a análise química do produto.

Segundo MALAVOLTA (1981), as causas das diferenças de qualidade encontradas, de acordo com a legislação, entre o teor garantido e o resultado da análise, podem ser atribuídas a:

erro tecnológico, quando houver falha no preparo devido à segregacão ou erro na pesagem ou na escolha dos ingredientes;

erro de amostragem, quando a amostra retirada não é representativa do lote ou;

erro analitico, quando os métodos de análise empreqados não são os mais adequados, ou se houver falha do operador ou do equipamento. 
Em vista do exposto, ao se discutir as etapas do controle de qualidade, aborda-se essencialmente as etapas que compõe o processo de análise química de fertilizantes.

Com relação aos fertilizantes, os procedimentos para a amostraqem, subamostraqem e determinaçōes analiticas estão definidos pela legislação oficial (BRASIL, 1983a e 1983b), que indicam as normas para coleta de amostra, redução, preparo e análise da amostra.

\subsubsection{Amostragem e redução da amostra}

De acordo com SILVA (1984), a homogeneidade ou heterogeneidade de um fertilizante é função direta do processo tecnológico de produção, e com base na estrutura da fabricação dos fertilizantes NPK, pode-se decidir sobre os cuidados que deverão existir no momento da amostragem.

segundo o mesmo autor, os fertilizantes fosfatados apresentam variaçōes sensiveis em sua composiçao, em função de serem obtidos à partir de rochas fosfáticas bastante diversificada quanto à sua composicão química e mineralóica. Por isso deve se tomar cuidado ao amostrar os superfosfatos, fosfatos de amônio e termofosfatos, que podem apresentar diferencas dentro do mesmo lote. Para os potássicos, que também são quase que exclusivamente resultante de beneficiamento de rochas, suas variações são menores podendo ser devido a origem ou ao processo de beneficiamento. Já os fertilizantes nitrogenados, produzidos à partir da amônia com alto teor de pureza e tendo em vista que sempre existe uma fase fluida no processo tecnológico, não deverão apresentar variaçōes no teor de nitrogênio.

Considerando a amostragem de uma maneira geral, o empreqo de amostragem probabilistica é a melhor recomendaça para se qarantir a representatividade da amostra, 
uma vez que eventuais diferencas entre a amostra e a população serão devidos ao acaso e, portanto, possíveis de serem eliminadas pelos métodos de análise estatística (SILVA, 1984). Também pode-se diminuir com maior eficiência a variância da média de uma amostragem, segundo BARBIN (1993), quando aumenta-se o número de individuos amostrados.

Quando se trabalha com material mais heteroqêneo a possibilidade de ocorrer erro na fase de amostragem é muito maior. Como exemplo, pode-se citar o caso das análises de solos onde HAUSER (1973) observou que 80-858 do erro total podem ser atribuidos à amostragem no campo e que 15-20웅 decorrem no trabalho de laboratório, compreendendo subamostraqem e determinação analítica, sendo que esta última raramente ultrapassa o valor de $5 \%$.

Para QUACKENBUSH \& RUND (1967), com base no conhecimento da proposta de amostragem e do grau de heterogeneidade do produto, pode-se decidir se a escolha de um ou vários sacos de fertilizantes devem ser efetuada por modelos ao acaso ou não. Observou ainda que a mistura de fertilizantes para a obtenção de amostras compostas não oferece nenhuma certeza de credibilidade da amostragem.

VERNE (1978) citou que o desvio total com relacão a média do teor de nutriente, é o resultado dos efeitos acumulativos de problemas básicos de fabricacão, procedimentos de amostragem, erro de amostragem, procedimentos analiticos, erro na preparaça dos relatórios analiticos, além de outros fatores.

GEHRKE (1972), pesquisando sobre os equipamentos e procedimentos usados para a amostragem de fertilizantes em 34 estados americanos, não encontrou maiores problemas para a coleta realizada em sacos de produtos com granulometrias diferentes, dispostos na horizontal, salientando que o erro devido à variação de composiçao entre sacos é 
muito maior que o erro de amostragem.

Para materiais complexos, a necessidade de trabalhar com um número maior de amostras nos leva a uma massa elevada de material a ser analisado, fazendo-se necessário o emprego de um processo de redução da amostra.

A tendência de segregação do material continua presente nos procedimentos de amostragem e sub-amostragem, mas é minimizada por técnicas de amostragem com sonda duplas e divisão por quarteadores do tipo "Jones" (TAYLOE, 1963; HANCOCK, 1983; HUBER Jr., 1984; WOODIS et alli, 1979).

Conforme observaram RODELLA \& ALCARDE (1994), por vezes se opta pela moagem de todo material para evitar a seqregacão durante o processo de reducão de amostras de fertilizantes seqreqantes no laboratório. Entretanto, esta opcão também pode afetar a representatividade do processo analitico, devido a absorção de umidade durante a manipulação prolongada do material.

PETTYGROVE \& SCHNEIDER (1979) observaram variâncias muito maiores que as permitida e recomendadas pelo AAPFCO - American Plant Food Control officials - em coleta de produto a granel com sonda e na bica. O fator que mais contribuiu para a magnitude dessas variâncias foi a descarga lenta no misturador de materiais com granulometria desuniforme, visto que a variância na coleta da amostra subestima a variabilidade inerente que ocorre nos fertilizantes misturados fisicamente.

\subsubsection{Determinações analiticas}

Sequndo ALCARDE (1991), o controle de qualidade de fertilizantes apoia-se fundamentalmente no trabalho de um laboratório químico, sendo que o sistema requer rapidez na emissăo dos resultados e economia de material. 
Os métodos oficiais utilizados na análise de fertilizantes NPK são tradicionais e clássicos (BRASIL, 1983b), que, apesar de possuírem alta precisão e exatidão, são métodos demorados e caros. Estudos desenvolvidos por ALCARDE (1982 e 1991), concluíram que esses métodos podem ser sensivelmente simplificados sem prejuízo significativo na precisão e exatidão dos resultados.

\subsubsection{Programas interlaboratoriais}

Segundo RODELLA \& BORGES (1989) para que o laboratório tenha confiança nos resultados encontrados, o uso de amostra padrão pode ser usado com vantagens em um programa interlaboratorial, onde os diversos laboratórios analisam uma mesma amostra, podendo-se comparar ao mesmo tempo a precisão da metodoloqia e a exatidão dos resultados.

Um proqrama interlaboratorial de controle de qualidade de análises representa uma importante contribuição para a manutenção da qualidade analitica do conjunto de laboratórios para a uniformidade dos resultados. (RAIJ et alli, 1987). São conhecidos diversos programas interlaboratoriais referentes à análise de materiais de interesse agronômico como solo, material vegetal e fertilizantes.

Segundo os mesmos autores (RAIJ et alli, 1987 e 1994), no Brasil existem quatro programas interlaboratoriais de análise de solo em andamento, sendo divididos por região e por método de análise empregado. No caso de são Paulo, o programa interlaboratorial evoluiu muito à partir de 1984, com a adoção da metodologia oficial, aumentando em 3928 o número de amostras analisadas no periodo entre 1982 e 1989.

Para a análise foliar, demonstrando a importância crescente desta técnica, teve infcio em 1982 um proqrama interlaboratorial com 15 laboratórios, e que após uma 
década já envolvia 40 laboratórios, responsáveis por cem mil amostras realizadas por ano (VITTI et alli, 1992; RAIJ et alli, 1994; PROCHONOW et alli, 1994).

ALCARDE (1994), destaca a importância de um proqrama interlaboratorial para fertilizantes, ao constatar a diminuicão dos coeficientes de variação dos resultados de determinação de nitrogênio. fósforo e potássio, obtidos no programa desenvolvido pela ANDA - Associação Nacional para Difusão de Adubos e Corretivos Agrícolas, ao longo de um período de vinte anos.

TERRY et alli (1991), estudando a variância e representatividade dos métodos da AOAC - Association of official Analytical Chemists dos E.U.A. para misturas NPK ensacadas, com teores de nutrientes entre 5 a $30 \%$, observaram que a maior variabilidade ocorre entre laboratórios e entre sacos amostrados, que no processo qlobal de análise.

Um trabalho básico foi aquele desenvolvido por OUACKENBUSH et alli (1966). O estudo foi desenvolvido em 23 laboratórios, sendo 12 oficiais e 11 industriais. Foram analisadas 5 misturas de fertilizantes sólidos, apresentando concentrações variando de 4 a $32 \%$ em nitroqênio, fósforo ou potássio e ainda um fertilizante liquido.

Considerando-se as variaçōes intralaboratoriais observaram que, embora os desvios padrōes dos resultados fossem pequenos, quer nos laboratórios industriais ou oficiais, na comparacão entre esses, a precisão média dos primeiros foi menor. A precisão foi menor na determinação de nitrogênio, do que nas determinaçōes de fósforo e potássio.

Ainda de acordo com QUACKENBUSH et alli (1966) nas variacões interlaboratoriais, a precisão dos resultados variou com o nutriente e com a magnitude da concentraçao do nutriente na amostra. Na maioria dos casos, a variaço dos 
resultados interlaboratoriais foi menor que a variacão intralaboratorial, o que pode parecer um resultado contraditório. Na avaliação da precisão da análise, os autores concluíram que as determinações em paralelo são de valor questionável e recomendam que repeticões sejam efetuadas com vários dias de intervalo. 
3. MATERIAL E MÉtodos

3.1. Contribuição das diversas etapas da análise de fertilizantes para a variabilidade dos resultados obtidos.

\subsubsection{Material}

o material utilizado constituiu-se de uma mistura de grânulos comercial, de fórmula 04-14-08, escolhida em função da sua importância na agricultura brasileira, sendo muito utilizada pelos agricultores em diversas culturas ${ }^{1}$.

\subsubsection{Etapas realizadas no campo}

\section{3:1.2.1. Local da amostragem}

A amostragem foi realizada num estabelecimento comercial situado a $60 \mathrm{Km}$ do estabelecimento produtor.

\subsubsection{Amostragem}

A amostragem foi realizada conforme a Portaria 01/8.3, referente à legislação sobre inspeç̃o e fiscalização da produção e do comércio de fertilizantes, corretivos, inoculantes e biofertilizantes destinados à agricultura (BRASIL, 1983a), que dispōe sobre as normas, procedimentos e equipa-

1 SILVA,C.A.P. (Associação Nacional para Difusão de Adubos $\theta$ Corretivos Agricolas) comunicaça pessoal 1994. 
mentos a serem utilizados na coleta de amostras de fertilizantes.

A amostragem foi realizada inserindo-se uma sonda de tubo duplo, em diaqonal no saco de fertilizante disposto horizontalmente, conforme mostrado na Fiqura 2 .

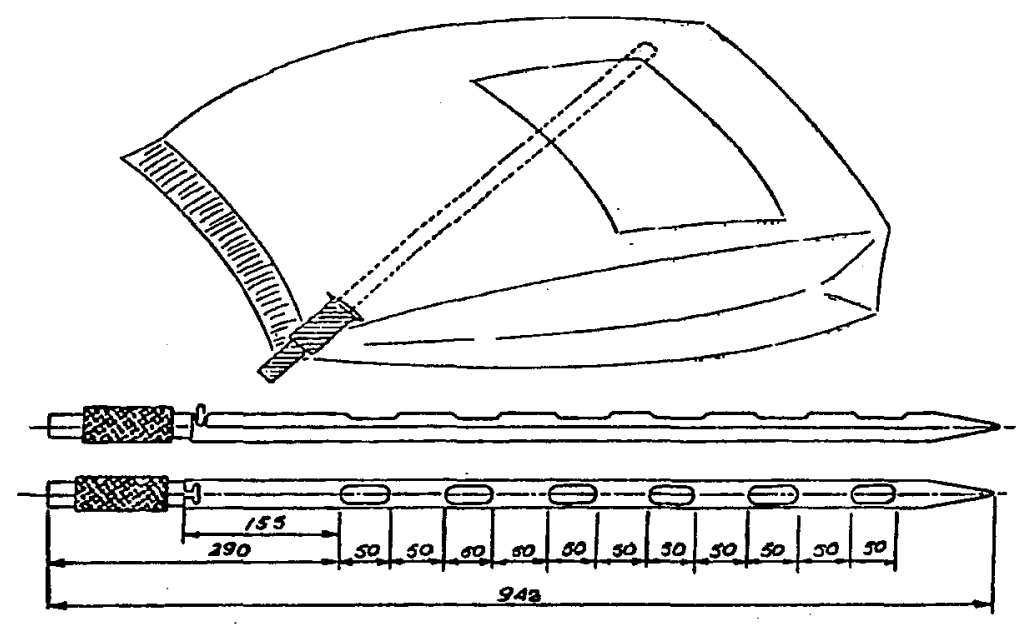

Fiqura 2. Esquema da sonda oficial para a amostragem de produtos ensacados e procedimento de coleta de fertilizantes ensacados. (BRASIL, 1983a).

Considerou-se um l.ote de 100 sacos de $50 \mathrm{~kg}$ de fertilizante, dos quais, obedecendo ao que indica Tabela 2 , selecionaram-se 20 sacos para serem amostrados pela sonda. 
Tabela 2. Número mínimo de sacos a serem amostrados conforme - tamanho do lote. (BRASIL, 1983a).

\begin{tabular}{cc}
$\begin{array}{c}\text { número de sacos } \\
\text { do lote }\end{array}$ & $\begin{array}{c}\text { número mínimo de } \\
\text { sacos amostrados }\end{array}$ \\
até 10 & todos \\
$11-50$ & 10 \\
$51-100$ & 20 \\
$101-2000$ & $20+28$ do lote \\
\hline
\end{tabular}

Esse mesmo procedimento foi repetido seis vezes, conforme o esquema experimental adotado. Os 100 sacos totais foram numerados sequencialmente e por sorteio os diferentes conjuntos de 20 sacos eram estabelecidos. Deve-se mencionar que todos os 100 sacos participavam de cada sorteio efetuado, de maneira que um mesmo saco pôde constituir o conjunto amostrado mais de uma vez.

\subsubsection{Redução da amostra}

As vinte porções de fertilizantes amostradas pela sonda, foram reunidas em um recipiente limpo e seco, totalizando em média $2 \mathrm{kq}$. O material foi homogeneizado e depois subdividido em duas porçoes por quarteação, em uma quarteador tipo "Jones", apresentado na Fiqura 3, uma destinada à análise física e outra a análise química.

Cada porção foi subdividida por quarteação até se obter quatro amostras homogêneas, denominando-se esse procedimento como "quarteação no campo". Para atender às finalidades do presente estudo, selecionaram-se portanto quatro "amostras de campo" destinadas à análise fisica e outras quatro "amostras de campo" para análise química. 
As frações da massa de fertilizantes subdivididas durante o processo de quarteação para obtenção das "amostras de campo" para análise física, foram pesadas afim de se avaliar a variabilidade decorrente do processo. Idealmente o processo de quarteação deve resultar em fracões de massas o mais similares possivel.

No procedimento de fiscalização usual, somente a metade desse esquema é conduzido, de maneira a se obter quatro amostras de campo. Destas, uma é enviada ao laboratório oficial para análise, duas são reservadas para uma eventual análise pericial e quarta é destinada ao produtor, como contramostra.

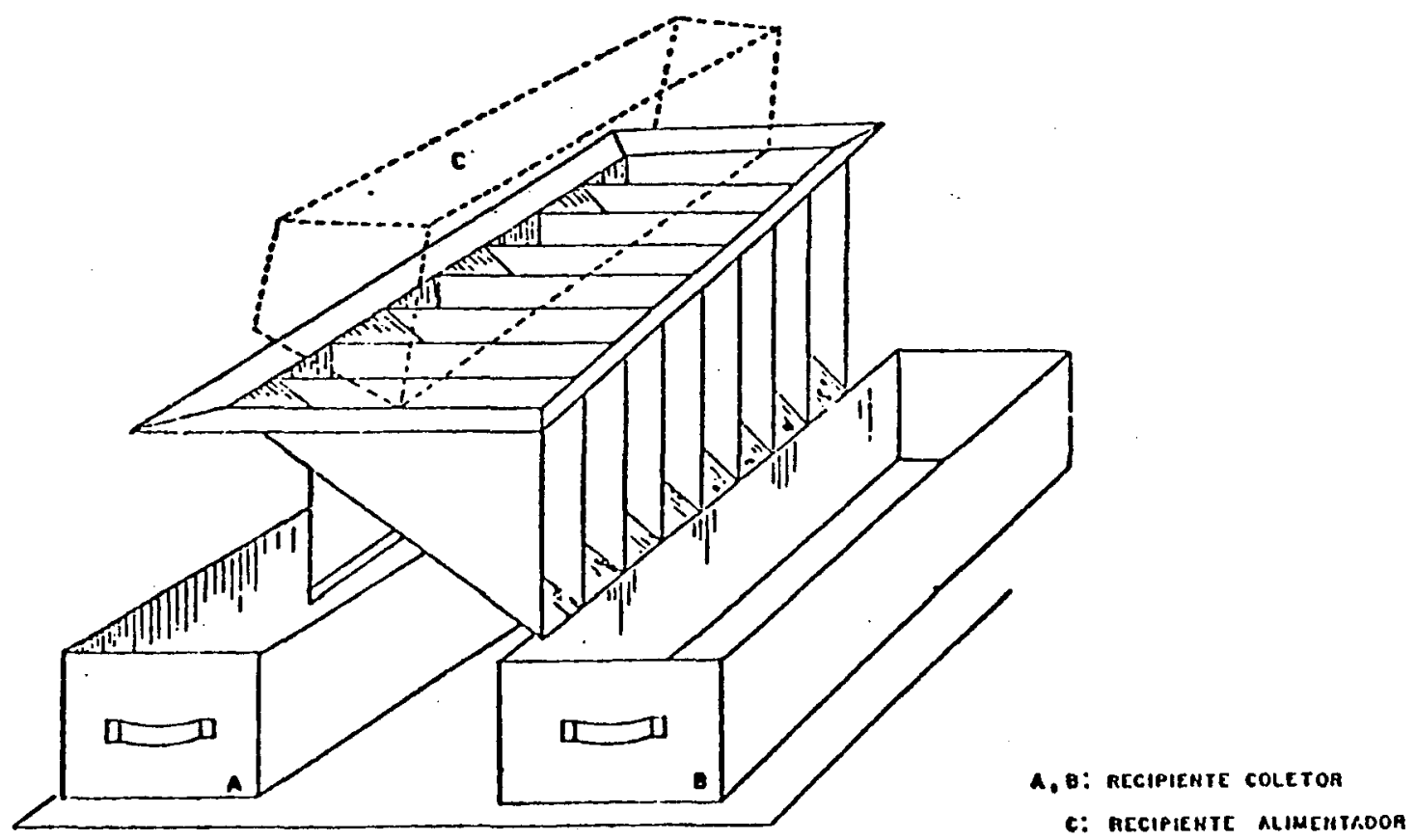

Fiqura 3. Representação esquemática do quarteador "tipo Jones". (BRASIL, 1983a). 
3.1.3. Etapas realizadas no laboratório

Para as determinação das fracões granulométricas e dos nutrientes nitrogênio, fósforo e potássio foram utilizados os métodos oficiais incluidos na legislação brasileira (BRASIL, 1983b).

\subsubsection{Análise granulométrica}

As quatro amostras destinadas à análise fisica foram peneiradas em um conjunto de peneiras de abertura de malhas $4,00 \mathrm{~mm}, 2,38 \mathrm{~mm}, 1,19 \mathrm{~mm}$, e $0,50 \mathrm{~mm}$, por 5 minutos na intensidade máxima, determinando-se assim a granulometria das partículas e a tendência de seqreqacão do material. Para a caracterização da compoșição quuímica de diferentes frações qranulométricas do material, foram incluidas as peneiras com abertura de malhas $2,00 \mathrm{~mm}, 1,00 \mathrm{~mm}$ e 0,42 $\mathrm{mm}$.

\subsubsection{Análises químicas}

\section{Preparo da amostra}

- As quatro amostras destinadas a análise química para determinação de nitrogênio, fósforo e potássio, foram submetidas à nova subdivisão por quarteação, na etapa denominada "quarteação de laboratório", resultando em oito subamostras de laboratório. No procedimento oficial essa subdivisão se destina a obter duas amostras de laboratório, a primeira para determinaça de granulometria e a sequnda para a análise química.

Cada amostra foi totalmente molda até passagem completa pela peneira ABNT $40(0.42 \mathrm{~mm}$ de abertura de malha). 
primeiramente em um liquidificador, que moe cerca de 70 a $90 \%$ da amostra, e o restante manualmente em almofariz de porcelana.

Depois de homogeneizada foi retirada uma aliquota de aproximadamente 10g, enviada ao laboratório, para que fossem efetuadas as determinaçōes de nitrogênio, fósforo e potássio, em duas repeticões. Nas determinacões analíticas foram empreqados os métodos oficiais incluidos na legislacão brasileira (BRASIL,1983b), dos quais se faz uma breve descricão a seguir.

\section{Determinação de nitrogênio total}

Para a determinação do nitrogênio total foi utilizado o método oficial de Kjedahl, empregando-se a liga de Raney para promover a amoniação das formas de nitrogênio.

A liga de Raney, constituida pela mistura $50 \%$ alumínio e 508 niquel, produz em meio ácido, hidroqênio nascente, que atua como redutor. o processo de redução é bastante seletivo e influenciado pelas condiçoses em que a reaça se processa. As formas mais comuns de ocorrência do nitrogênio nas misturas fertilizantes são a amoniacal, nítrica e a amídica. Em meio ácido o nitrogênio na forma amídica da uréia é transformado para a forma amoniacal, por outro lado, o hidrogênio nascente atuando sobre a forma nitrica, reduz o nitrogênio resultando também na forma amoniacal.

Alcalinizando fortemente o meio, faz-se com que o ion amônio, no qual todas as formas de nitrogênio presentes no fertilizantes foram transformadas, passe para a forma de amônia. Por meio de destilação, a amônia é deslocada e reage com volume conhecido de soluça padronizada de ácido sulfúrico. A titulaçăo do ácido remanescente permite quanti- 
ficar o teor de nitrogênio na solução de amostra.

Determinação de fósfóro solúvel em solucão neutra de citrato de amônio mais áqua

Na quantificacão de fósforo nos fertilizantes é necessário se avaliar a fracão solúvel do elemento, para que o teor determinado indique a disponibilidade do nutriente aos veqetais. Na determinação do fósforo na mistura 14-4-8 estudada, foi utilizado o método oficial direto de extração de fósforo em solucão neutra de citrato de amônio mais áqua (CNA+áqua). Tendo em vista as diversas formas de fósforo existentes, com diversos graus de solubilidade, a solucão neutra de citrato de amônio é o extrator que melhor expressa o fósforo utilizado pelas plantas, solubilizando com eficiência diversas formas do nutriente, exceto o fosfato tricálciCo, as apatitas e o pirofosfato de cálcio (ALCARDE, 1991).

o processo de extração consta da agitação da amostra suspensa em $100 \mathrm{ml}$ de solução neutra de citrato de amônio, a $65^{\circ} \mathrm{C}$, por 60 minutos. A determinação do fósforo solubilizado é feita por gravimetria, separando o nutriente na forma de fosfomolibdato de quinolina.

Determinacão de potássio

No método fotométrico de chama oficial, a extração do potássio é efetuada em áqua, visto que as fontes de potássio nas misturas, geralmente cloreto ou sulfato de potássio, são bastante solúveis. A determinaça de potássio é facilmente conduzida por fotometria de chama de emissão, diretamente no extrato aquoso. o método baseia-se na medida da radiação emitida quando átomos de potássio, após 
terem sido excitados pela energia térmica de uma chama, retornam ao estado fundamental.

\subsubsection{Análise estatistica}

3.1.4.1. Variabilidade nos resultados de aná1ise química: determinações de nitrogênio, fósforo e potássio.

Foram analisados, para cada nutriente considerado, os componentes de variancia no modelo de classificacão hierárquica (BARBIN, 1993), mais indicado para os objetivos deste estudo. Baseiando-se na repetiço das operações que compõe as diferentes etapas estudadas: amostragem, quarteação no campo, preparo da amostra no laboratório e determinação analitica, constitui-se num esquema que reflete a dependência entre elas, conforme mostra o quadro de análise de variância apresentado na Tabela 3 .

onde:

$$
\text { Modelo Matemático: } Y_{i j k l}=m+a_{i}+b_{i j}+c_{i j k}+d_{i j k l}
$$

$$
\begin{aligned}
& i=6=\text { número de amostragens; } \\
& \mathbf{j}=4=\text { preparo da amostra; } \\
& \mathbf{k}=2=\text { preparo da amostra no laboratório; } \\
& 1=2=\text { determinação analitica. }
\end{aligned}
$$


Tabela 3. Quadro de análise de variância dos resultados de análise química no modelo de classificação hierárquica.

\begin{tabular}{lrll}
\hline Causa da Variacão & GL & QM & \multicolumn{1}{c}{ E(QM) } \\
\hline Amostraqem(am) & 5 & sQa/GLam & $\sigma^{2}+2 \sigma^{2} p+4 \sigma^{2} q+16 \sigma^{2} a m$ \\
Quarteaçõo( $q$ ): am & 18 & sQq/GLq & $\sigma^{2}+2 \sigma^{2} p+4 \sigma^{2} q$ \\
Preparo(p): q : am & 24 & sQp/GLp & $\sigma^{2}+2 \sigma^{2} p$ \\
Determinação:p:q:am & 48 & sQd/GLd & $\sigma^{2}$ \\
\hline Total & 95 & & \\
\hline
\end{tabular}

$E(Q M)=$ esperança do quadrado médio ou componentes de variância.

Na tabela 3 , indica-se através da representaçao usual, que o fator de variaça que antecede o sinal ":" esta sendo considerado em relação aos demais.

3.1.4.2. Distribuicão das massas de fertilizantes no processo de quarteação

Na análise do comportamento do quarteador do tipo "Jones" utilizado, foram determinados os componentes de variância no modelo de classificação hierárquica, indicado a sequir, conforme o quadro de análise de variância apresentado na Tabela 4 .

onde :

Modelo Matemático: $Y_{i j k}=m+a_{i}+b_{i j}+c_{i j k}$

$$
\begin{aligned}
& i=6=\text { numero de amostragens; } \\
& i=4=\text { preparo da amostra; } \\
& k=2=\text { preparo da amostra no laboratório; }
\end{aligned}
$$


Tabela 4. Quadro de análise de variância das massas obtidas na redução da amostra no modelo de classificação hierárquica.

\begin{tabular}{lccc}
\hline Causa da Variação & GL & QM & E(OM) \\
\hline Amostras(am) & 5 & SQam/GLam & $\sigma^{2}+2 \sigma^{2} q+8 \sigma^{2} a m$ \\
Ouarteacão(q):am & 18 & SQq/GLq & $\sigma^{2}+2 \sigma^{2} q$ \\
Preparo(p): : :am & 24 & sQp/GLp & $\sigma^{2}$ \\
\hline Total & 47 & & \\
\hline
\end{tabular}

$\mathrm{E}(\mathrm{QM})=$ esperança do quadrado médio ou componentes de variância.

o estudo de componentes de variância permitirá avaliar a contribuição das diferentes etapas da análise para a variabilidade do resultado final das determinações. Essa abordagem é bastante interessante, pois permite identificar as etapas da marcha geral de análise que deverão receber cuidados ainda maiores na sua execução.

O esquema mostrado na Fiqura 4 permite uma visão geral das etapas envolvidas no estudo de composicão de variância discutido anteriormente. Conforme pode se constatar, ele foi estabelecido em função do procedimento oficial de coleta e preparo de amostras para análise de fertilizantes em viqor. E importante ressaltar, que ao se considerar a variabilidade dos resultados de composicão quimica na amostragem, por exemplo, esta-se referindo à variabilidade de composição de amostras compostas do fertilizante. 


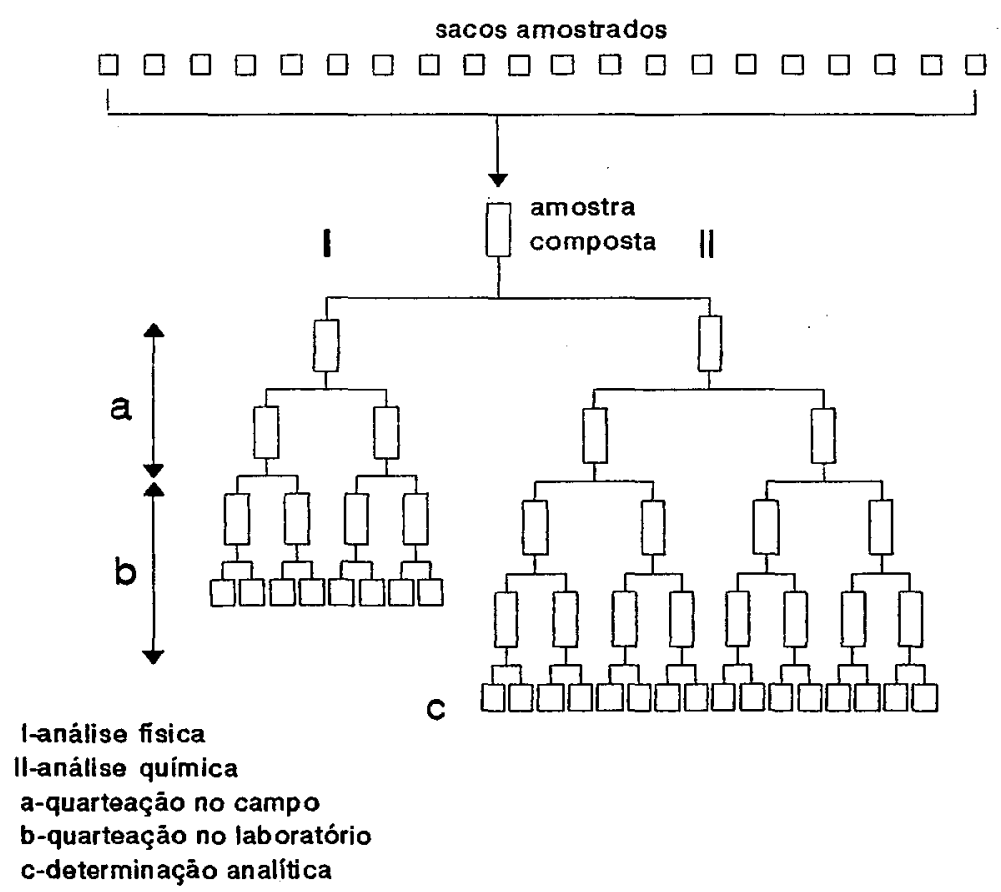

Fiqura 4. Esquema das etapas envolvidas no processo de amos traqem e determinacooes realizadas no laboratório.

3.1.4.3. Variabilidade nos resultados de análise granulométrica

Este estudo objetivou avaliar como as etapas de amostragem e reducão da amostra afetam a precisão da análise da composição qranulométrica das partículas. Os dados foram analisados no esquema fatorial, onde os fatores amostragem e quarteação, foram analisados para cada fração granulométrica considerada. Na Tabela 5 é mostrado o quadro da análise de variância. 
Tabela 5. Quadro de análise de variâncià dos resultados da análise granulométrica.

\begin{tabular}{lc}
\hline Causa da Variação & GL \\
\hline Amostragem & 5 \\
Quarteação & 3 \\
Residuo & 15 \\
\hline Total & 23 \\
\hline
\end{tabular}

3.2. Estudo interlaboratorial: variabilidade dos teores de nitrogênio, fósforo e potássio em função do método e do laboratório.

Os estudos descritos anteriormente visaram avaliar os fatores de variação dos resultados da análise de fertilizantes, considerando o processo em todas suas etapas. As determinacōes analiticas foram então conduzidas em um único laboratório. Para se avaliar o fator laboratório como causa de variação dos resultados considerou-se os resultados de um estudo interlaboratorial envolvendo laboratórios oficiais de fiscalização do Ministério da Agricultura.

\subsubsection{Laboratórios participantes}

Participaram do presente estudo o laboratório de análise de fertilizantes do Departamento de Química da Escola Superior de Agricultura "Luiz de Queiroz" e os laboratórios oficiais de fiscalização do Ministério da Agricultura, das seguintes unidades da federação: Rio Grande do Sul; Santa Catarina, Paraná, Goiás e Pará. 
3.2.2. Material utilizado

Aproximadamente à cada dois meses, à partir de meados de 1987, eram enviadas aos laboratórios participantes uma amostra de um fertilizantes mineral simples comercial e uma amostra de uma mistura de grânulos comercial, ou formulada no laboratório à partir de fertilizantes simples comerciais. Foram efetuadas um total de 17 remessas, sendo que as amostras já se encontravam moídas e prontas para serem analisadas, desde que se pretendia estudar apenas variaçōes nas determinações analíticas.

\subsubsection{Fertilizantes minerais simples}

Foram selecionados os principais fertilizantes simples usados tanto pelas empresas na formulação de misturas de grânulos NPK, como diretamente pelos agricultores., Os fertilizantes enviados nas diversas remessas de amostras encontram-se na Tabela 6 .

Tabela 6. Frequência de remessa e relação dos fertilizantes simples enviados para análise no programa interlaboratorial.

\begin{tabular}{lc}
\hline Produto & Frequência \\
\hline Uréia & 1 \\
Nitrato de amônio & 1 \\
Fosfato diamônico & 3 \\
Superfosfato simples & 3 \\
Superfosfato triplo & 2 \\
Fosfato natural & 4 \\
Termofosfato & 1 \\
Cloreto de potássio & 2 \\
\hline
\end{tabular}


3.2.2.2. Fertilizantes minerais mistos

As misturas de grânulos utilizadas foram misturas comerciais e misturas preparadas em laboratório à partir de fertilizantes minerais simples comerciais. As misturas fertilizantes utilizadas continham nitrogênio, fósforo e potássio em concentrações variáveis, apresentadas na Tabela 7 .

Tabela 7. Número de amostras de fertilizantes minerais mistos estudadas em cada intervalo de concentração de nutrientes.

\begin{tabular}{ccccc}
$\begin{array}{c}\text { Intervalo de concentração } \\
(8)\end{array}$ & $\begin{array}{c}\text { número de amostras estudadas } \\
\mathrm{N}\end{array}$ & $\begin{array}{c}\mathrm{P}_{2} \mathrm{O}_{5} \\
\mathrm{~K}_{2} \mathrm{O}\end{array}$ \\
\hline $0-5$ & 4 & 3 & 4 \\
$6-10$ & 3 & 3 & 3 \\
$11-20$ & 4 & 6 & 4 \\
$21-30$ & 3 & 5 & 4 \\
$>30$ & 3 & 0 & 2 \\
\hline
\end{tabular}

Observa-se que houve a preocupação de incluir fertilizantes contendo teores de nutrientes diferenciados, de modo que os laboratórios fossem testados nos mais diferentes niveis de concentração dos nutrientes.

\subsubsection{Preparo das amostras}

No caso de fertilizantes simples, o material escolhido foi homogeneizado e moldo para passar na peneira ABNT $20(0.84 \mathrm{~mm}$ de abertura de malha). Depois de nova homogeneizaçao, foram separadas e enviadas as amostras aos laboratórios. 
Para as misturas comerciais procedeu-se a homogeneização manual do produto. Já para as misturas preparadas no laboratório, as matérias primas foram misturadas e homogeneizadas no misturador descrito por ALCARDE (1991) que é apresentado na Figura 5. Depois de homogeneizadas as misturas foram moídas até passarem na peneira ABNT $40(0.42 \mathrm{~mm}$ de abertura de malha), nova homogeneizaça no misturador, quando as amostras foram separadas e enviadas aos laboratórios.

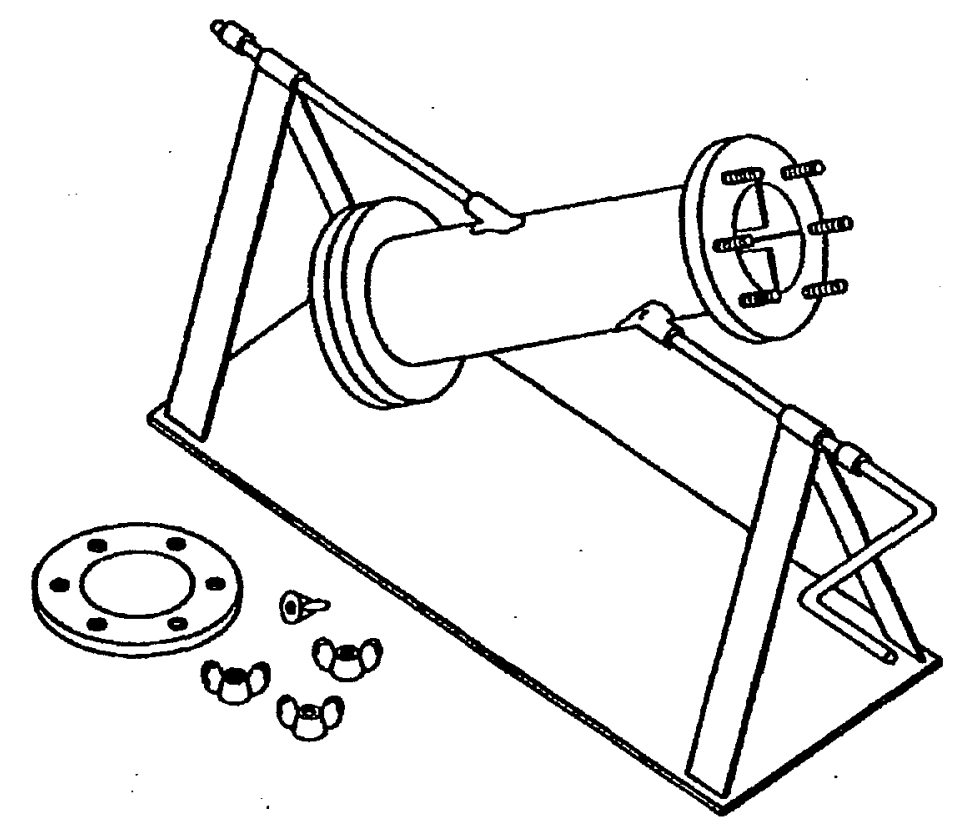

Fiqura 5. Misturador de fertilizantes idealizado por ALCARDE (1991).

\subsubsection{Determinações analiticas}

Para as diversas determinaços foram utilizados os métodos oficiais brasileiros (BRASIL, 1983b) e os métodos simplificados propostos por ALCARDE (1982 @ 1991). 
3.2.4.1. Nitrogênio

o nitrogênio total foi determinado sempre pelo método de Kieldahl, no qual se determina por volumetria de neutralização o nitrogênio na forma amoniacal. Na transformação das formas de nitrogênio eventualmente presentes para nitroqênio amoniacal, foram utilizados os métodos oficiais do ácido salicílico e da liga de Raney. No método simplificado, - nitrogênio foi determinado em aliquota extrato aquoso.

Método do ácido salicilico

Fundamenta-se na amoniação do nitrogênio nitrico na presença de $\mathrm{H}_{2} \mathrm{SO}_{4}$ a 988 e de ácido salicilico em temperatura ambiente e depois levemente aquecido. Como o ácido salicilico só consegue reduzir 998 do nitrogênio na forma nitrica, é acrescentado zinco ou tiossulfato para completar a reaçăo. Se existir formas orqânicas de nitrogênio na amostra, estas deverão ser posteriormente amoniadas na presença de catalizadores como Hgo, Ho metálico, Cuso 4 ou $\mathrm{Na}_{2} \mathrm{SeO}_{3} \cdot 5 \mathrm{H}_{2} \mathrm{O}$, visto que o processo seria muito lento apenas na presença do ácido sulfúrico. Ainda para se aumentar a temperatura da diqestão são usados sais inertes como $\mathrm{K}_{2} \mathrm{SO}_{4}$ ou $\mathrm{Na}_{2}-$ $\mathrm{so}_{4}$. As desvantagens deste método são a utilização de ácido sulfúrico concentrado, que é perigoso; a restrição à presença da água, e a consequente exclusão dos fertilizantes fluidos e o emprego de catalizadores, como o mercúrio metálico, que $e$ muito tóxico. 


\section{Método da liga de Raney}

As características básicas deste procedimento já foram mencionadas em 3.1.3.2. O método da liga de Raney, apresenta grandes vantagens em relação ao método do ácido salicilico, por ser mais rápido, menos tóxico, servir para todas as formas de nitrogênio e a fertilizantes tanto sólidos como fluidos. JOHNSON et alli (1974), depois confirmado por ALCARDE \& PAULINO (1984), observaram que a liga de Raney possui a função catalítica para a digestão das formas orgânicas do nitrogênio.

\section{Método simplificado}

Fundamenta-se na determinação do nitrogênio total, à partir de um extrato aquoso, sendo aplicável a amostras contendo nitrogênio nas formas amoniacal, nitrica e amídica da uréia. A simplificação do método consiste em preparar um mesmo extrato aquoso para as determinações de nitrogênio, fósforo solúvel em água e potássio. A destilação da amônia, resultante da alcalinização da solução contendo o fon $\mathrm{NH}_{4}^{+}$, é conduzida em microdestilador.

\subsubsection{Fósforo}

\section{Extração}

A extração de fósforo que é utilizada, depende do tipo de fertilizante fosfatado usado, podendo resultar na obtenção de teor: total, solúvel em água, solúvel em ácido citrico ou solúvel em CNAtágua. 


\section{Fósforo total}

Este método se aplica obrigatoriamente na análise de fosfato natural, fosfato natural parcialmente acidulado, termofosfato magnesiano, termo-superfosfato e hiperfosfato, apresentando um valor relativo sobre a capacidade potencial do fertilizante. Efetua-se a digestão da amostra com soluções concentradas de ácidos oxidantes, sendo todo fósforo solubilizado e convertido em ácido fosfórico. No método oficial o fon ortofosfato é precipitado como fosfomolibdato de quinolina, que é determinado por gravimetria. No método simplificado, o íon ortofosfato transformado em ácido molibdovanadofosfórico, e determinado por colorimetria.

\section{Fósforo solúvel em água}

Esta determinação é obrigatória para o fosfato natural parcialmente acidulado, termo-superfosfato, nitrofosfato, superfosfato simples, superfosfato duplo, superfosfato triplo, fosfato monoamônico e fosfato diamônico, avaliando o teor de fósforo prontamente solúvel.

No procedimento oficial, a extração se dá pela lavagem da amostra sucessivamente, com uma quantidade conhecida de áqua até atingir um volume de $250 \mathrm{ml}$. No método simplificado, foi estabelecido um processo mais fácil de extração, que consiste na agitação da amostra com $125 \mathrm{ml}$ de áqua por 15 minutos.

Como descrito acima, a determinacão do fósforo solúvel em áqua pelo método oficial é por gravimetria na forma de fosfomolibdato de quinolina, enquanto que no método simplificado é por colorimetria na forma de ácido molibdovanadofosfórico. 
Fósforo solúvel em CNA + áqua

A determinação do fósforo solúvel em CNA+água é obriqatória na análise de fosfato monoamônico, fosfato diamônico, fosfosulfato de amónio, superfosfato simples, superfosfato triplo, nitrofosfato, superfosfato duplo, fosfato natural parcialmente acidulado, fosfato bicálcico e todos fertilizantes mistos.

As características básicas do método oficial já foram comentadas em 3.1.3.2. No procedimento simplificado substitui-se a extração sob agitação a $65^{\circ} \mathrm{C}$, pela extração a ebulição, sendo a determinação do fósforo efetuada por colorimetria.

\section{Determinação de fósforo}

O método oficial de determinação das diversas formas de fósforo: total, solúvel em água, solúvel em ácido citríco ou solúvel em CNA+áqua, fundamenta-se na precipitacão do ion ortofosfato como fosfomolibdato de quinolina, o qual é seco e pesado.

No método simplificado, para a determinação do ion ortofosfato após a extraça das diferentes formas de fósforo já citadas, se emprega a determinação colorimétrica baseada na formação do ácido molibdovanadofosfórico.

\subsubsection{Potássio}

No estudo interlaboratorial a determinação de potássio foi conduzida por três diferentes métodos analiticos: método oficial do tetrafenilborato de sódio (TFBS); método fotométrico de chama oficial e método fotométrico de 
chama simplificado.

o método oficial do TFBS, baseia-se na extracão do potássio em solucão de oxalato de amônio, seguindo-se precipitação do nutriente com quantidade conhecida e em excesso de TFBS e posterior titulacão da quantidade remanescente de TFBS, com solução padrão de sal quaternário de amônio.

o método fotométrico de chama simplificado é semelhante ao método fotométrico de chama oficial citado em 3.1.3.2. Difere quanto a utilização do mesmo extrato aquoso utilizado para a determinação do nitrogênio e pelo uso de um intervalo maior da curva de calibração do fotômetro de chama.

\subsubsection{Análise estatística}

\subsubsection{Análise estatística básica}

Calculou-se a média, desvio padrão e coeficiente de variação dos resultados obtidos pelos laboratórios para cada nutriente, método analitico e amostra.

\subsubsection{Desempenho dos laboratórios}

Para cada nutriente e para cada método analitico empregado, confrontou-se o desempenho dos laboratórios para todas as amostras de fertilizantes enviadas. A análise estatistica foi efetuada segundo o esquema de blocos casualizados, considerando-se as amostras como blocos, visto que apresentavam teores de nutrientes bastante diferenciados, conforme pode se constatar nas Tabelas $6 \ominus 7$. 
3.2.5.3. Comparação entre métodos analiticos

Englobando-se os dados obtidos por todos os laboratórios participantes e para todas as amostras analisadas, confrontaram-se os resultados fornecidos pelos diferentes métodos analiticos empregados para a determinacão de nitrogênio, fósforo e potásio.

Foi efetuado o cálculo de regressão linear entre os valores fornecidos pelos métodos analiticos comparados e, conforme recomenda YOUDEN (1947), foram avaliadas as maqnitudes dos coeficientes linear e anqular da reta obtida. Para resultados exatamente concordantes seriam obtidos valores zero e um, respectivamente para os citados parâmetros, obtendo-se uma equação $y=x$. Na prática os valores dos coeficientes são testados pelo teste $t$.

Quando o coeficiente linear é estatisticamente diferente de zero, admite-se a ocorrência de uma diferenca aditiva entre os métodos, ou seja independente da concentracão. Por outro lado, se o coeficiente angular for estatisticamente diferente de um há evidências de diferença proporcional entre os resultados de cada método confrontado. 


\section{RESULTADOS E DISCUSSÃO}

4.1. Contribuição das diversas etapas da análise de fertilizantes para a variabilidade dos resultados obtidos

Inicialmente, deve ser ressaltado que se considera neste estudo a variaçao dos resultados das amostras compostas obtidas de acordo com o procedimento oficial (Brasil, 1983a). Deste modo, como as amostras são constituídas no presente caso por sondagens efetuadas em vinte sacos, a variabilidade da composiçao do fertilizante, observada através dos resultados das amostras, é atenuada por um fator de $\sqrt{20}$. Isso decorre do erro padrão da média equivaler ao desvio padrão da população, dividido pela raiz quadrada do nuimero de observaçōes.

4.1.1. Distribuição das massas de fertilizante no processo de quarteação

Durante o processo rotineiro de amostragem de fertilizantes para fiscalizaçao, é comum observar diferenças entre as massas das quatro amostras de campo resultantes do processo.

O presente estudo pretendeu avaliar a variação da quantidade de material selecionada como amostra para análise em função das etapas de trabalho. Esses etapas são: a coleta de material através da sonda dupla de amostragem, a quarteação da quantidade amostrada no campo e a quarteação da amostra de campo no laboratório.

Os resultados desse estudo, apresentados na Tabela 8, evidenciam que 44,08 da variacão na quantidade fertilizantes que constitui a amostra, é resultante do pro- 
cesso de amostragem nos sacos com a sonda dupla. Essa variacão mostra que as massas de fertilizantes obtidas através da sonda são estatisticamente diferentes, o que se explica pela diferenca na granulometria das particulas que constituirão o volume coletado pela sonda. Se a maior proporção das particulas for de diâmetro pequeno, pó por exemplo, a massa amostrada será maior do que no caso de partículas grandes forem selecionadas. Medidas da massa da amostra retirada pela sonda em sacos da mistura 4-14-8, tomadas ao acaso, forneceu um coeficiente de variação de $9 \%$.

A quarteação no campo por sua vez, respondeu por 49,88 da variância total das massas das amostras, valor esse muito superior ao referente à quarteaço em laboratório, iqual a 6,2\%. Essa diferenca se deve ao procedimento denominando "quarteação de campo" ser na realidade um processo de oito etapas de redução de amostra no quarteador de Jones. enquanto que no laboratório, a quarteacão se efetúa em uma única etapa.

Tabela 8. Composicão de variância das massas de amostras de fertilizantes obtidas no processo de amostragem .

\begin{tabular}{lcc}
\hline Causas de Variação & Variância (8) & \multicolumn{1}{c}{$F$} \\
\hline Amostragem & 44,0 & $4,33^{\mathrm{k \hbar}}$ \\
Quarteação: Am & 49,8 & $17,16^{\text {** }}$ \\
Preparo:Q: Am & 6,2 & \\
\hline Total & 100,0 & \\
\hline
\end{tabular}

Coeficiente de variação $=2,58$

A variação da massa amostrada decorrente da operação de quarteacão pode ser atribuida a procedimentos sistemático de trabalho. Como várias etapas de quarteação no 
campo se sucedem na reduça de grandes quantidades amostrada$s$, a tendência é que as discrepâncias se acumularem.

\subsubsection{Análise granulométrica}

4.1.2.1. Caracterização da mistura de grânulos estudada

A mistura fertilizante estudada, de fórmula 4-14-8, foi submetida à análise granulométrica fornecendo os resultados mostrados na Tabela 9 .

A USAID - United States Agency for International Development - especifica que na compra de fertilizantes para seus programas, no mímimo $90 \%$ do fertilizante deve apresentar entre 1,00 e $3,35 \mathrm{~mm}$ de diâmetro de particulas (USAID, 1977). Observa-se entło que por esse critério a mistura estudada pode ser considerada homogênea do ponto de vista granulométrico, visto que 93,78 da massa apresenta arânulos com tamanho entre 1,19 e $4,00 \mathrm{~mm}$.

Esses resultados indicam que essa mistura não apresenta arande tendência para segregar, pois de acordo com HOFFMEISTER (1979), a tendência de seqreqąão aqrava-se quando o fertilizante apresenta maior proporcão de sua massa em partículas maiores que $4,00 \mathrm{~mm}$ e menores que $0,30 \mathrm{~mm}$.

A imagem fotográfica das fraçōes granulométricas selecionadas evidencia que a composicão químicas das mesmas é diferente. o cloreto de potássio, por sua coloraça característica, aparece com maior evidência na fraçōes de diâmetro: maior que $4 \mathrm{~mm}$ e entre 0,42 e $1,19 \mathrm{~mm}$. Consideracōes sobre os nutrientes nitrogênio e fósforo deixam se serem feitas por não serem conhecidas as fontes desses elementos. 
A diversidade da composição química das diferentes frações fica claramente estabelecida quando se observam os resultados analíticos. Nenhuma das fraçōes corresponde à garantia do produto. Deve-se considerar ainda que a presenca de enchimento pode ser evidenciada sobretudo pelos resultados da fraç̃o menor que $0,42 \mathrm{~mm}$. 
Tabela 9. Imagens, porcentagens da massa total e resultados de análise químicas, das diferentes frações granulométricas em que foi fracionada a mistura de fertilizantes 4-14-8 estudada.

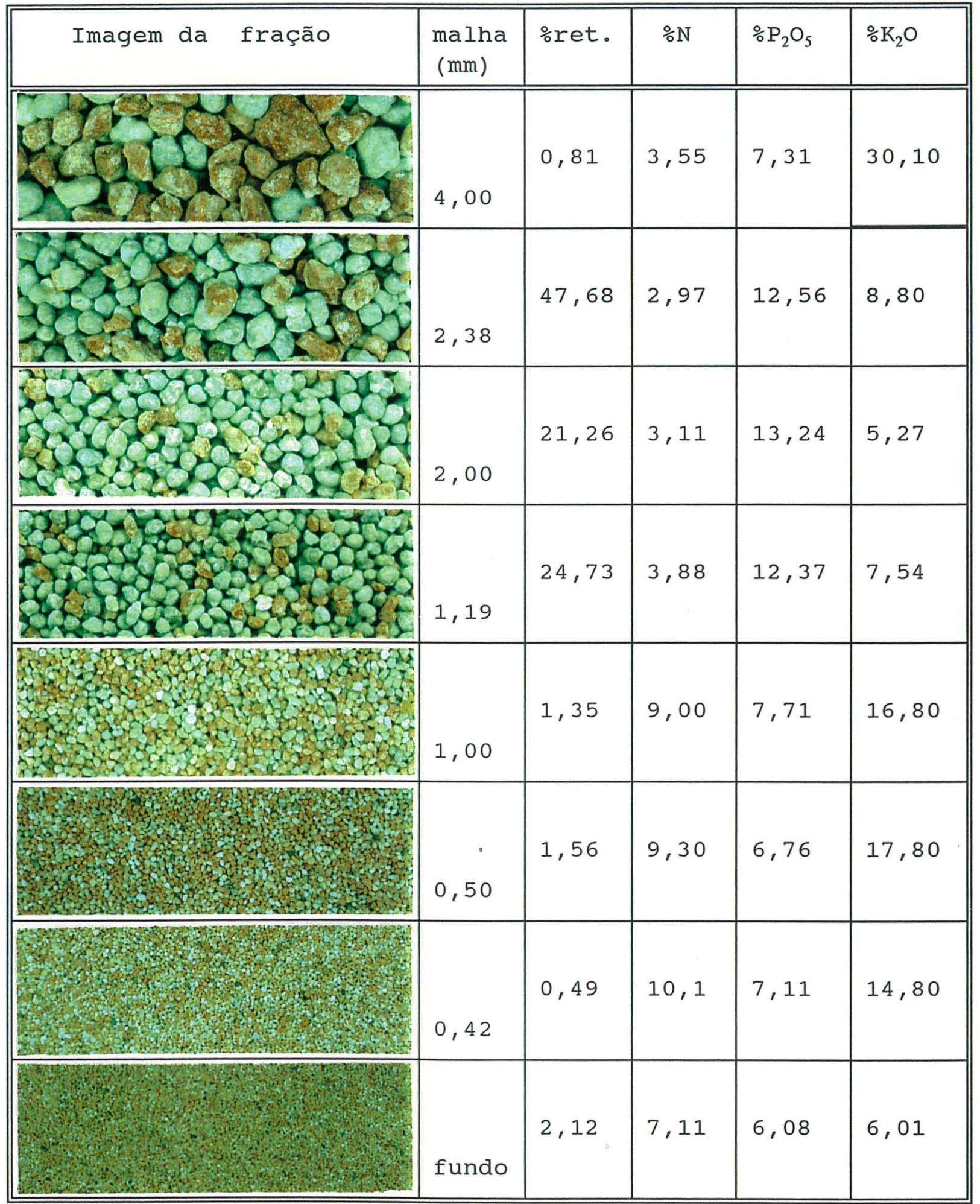




\subsubsection{Variabilidade dos resultados de análise granulométrica}

Conforme se pode observar pelos dados da Tabela 10, as etapas de coleta de amostra e quarteação no campo, influenciam a variação dos resultados de análise granulométrica, apenas quando se consideram as frações extremas. Esse fato pode ser explicado ao considerar que as particulas mais finas e as de maior diâmetro são aquelas que segregam de maneira mais acentuada.

Tabela 10. Efeito da amostragem e quarteação no campo sobre a precisão dos resultados da análise granulométrica.

\begin{tabular}{ccc}
\hline diâmetro de partícula & \multicolumn{2}{c}{ valor de $F$} \\
$(\mathrm{~mm})$ & amostragem & quarteação \\
\hline$>4,00$ & $5.29^{\star \star}$ & $3,76^{\star}$ \\
$2,38-4,00$ & 0,51 & 1,29 \\
$1,19-2,38$ & 1,45 & 1,02 \\
$0,50-1,19$ & 2,29 & $5,07^{\star}$ \\
$<0,50$ & $8,09^{\star \star}$ & 0,94 \\
\hline
\end{tabular}

significância estatística testada a $5 \%(*)$ e $1 \%(* *)$ de probabilidade

4.1.3. Variabilidade nos resultados de análise química: determinações de nitrogênio, fósforo e potássio

Conforme se considerou no item 4.1.2.1, a granulometria da mistura estudada era relativamente uniforme, não favorecendo portanto a segregação dos componentes. Assim sendo, a variabilidade dos resultados em termos absolutos foi relativamente pequena, conforme pode constatar pelos valores de coeficientes de variação que serão apresentados nos resultados da determinações analiticas discutidas a seguir. 
4.1.3.1. Determinacão de nitrogênio

A partir dos dados apresentados na Tabela 11, pode-se afirmar que determinacão analitica foi a etapa da análise que mais contribuiu em termos relativos para a variância dos resultados da determinacão de nitrogênio total na mistura ferti1 izante estudada, correspondendo a 45,18 da variância total.

Tabela 11. Composição da variância do resultado da análise de fertilizante para a determinação de nitrogênio total.

\begin{tabular}{lcc}
\hline Causas de Variação & Variância $(8)$ & teste F \\
\hline Amostragem & 24,9 & $4,49^{\star \star}$ \\
Quarteação:am & 4,5 & 1,18 \\
Preparo:q:am & 25,5 & $2,13^{\star k}$ \\
Determinação:p:q:am & 45,1 & \\
Total & 100,0 & \\
\hline
\end{tabular}

Coeficiente de Variação $=3,33 \%$

Em seguida, em ordem decrescente de contribuição, vem o preparo de amostra no laboratório com 25,58 e a amostragem dos sacos, que é a primeira etapa do processo de análise, com 24,98. A etapa de quarteação no campo só colaborou com 4,58. Essas observaçōes são corroboradas pelos valores obtidos para o teste F: houve efeito significativo ao nivel de 18 de probabilidade tanto para amostragem, como para o preparo da amostra no laboratório, ou seja, as operaçōes de amostragem e redução de amostra no laboratório, ao contrário da quarteacão no campo contribuiriam siqnificativamente para a variabilidade do resultado final. 
4.1.3.2. Determinação de fósforo solúvel em CNA + água

Os resultados da determinação de fósforo em CNA+água, foram afetados pela amostragem, sendo que 71,58 da variância total dos resultados pode ser atribuida a essa etapa, com significância estatística ao nível de $1 \%$ de probabilidade. A determinação analítica contribuiu para $21,3 \%$ da variância, enquanto que as etapas de quarteação, tanto no campo como no laboratório não afetaram os resultados.

Tabela 12. Composição da variância do resultado da análise de fertilizante para a determinação de fosforo solúvel em CNA+água.

\begin{tabular}{lcc}
\hline Causas de Variação & Variância (8) & teste F \\
\hline Amostragem & 71,5 & $29,24^{\star \star}$ \\
Quarteação:am & 2,5 & 1,32 \\
Preparo:q:am & 4,7 & 1,44 \\
Determinação:p:q:am & 21,3 & \\
\hline Total & 100,0 \\
\hline
\end{tabular}

Coeficiente de Variação $=2,008$

4.1.3.3. Determinação de potássio

Conforme se pode constatar na Tabela 13, os resultados da determinaçāo de potássio pelo método fotométrico de chama oficial, foram afetados pela etapas de quarteação no campo e determinacão analitica, responsáveis por 42,0 e 37,38 da variancia total respectivamente.

Na análise dos resultados apresentados anteriormente pode-se admitir como ponto de partida que a variacão de 
resultados em funça da amostragem do fertilizante decorre da variabilidade de composiça do produto entre os sacos e durante - processo de coleta de amostra pela sonda.

Tabela 13. Composição da variância do resultado da análise de fertilizante para a determinacão de potássio.

\begin{tabular}{lcc}
\hline Causas de Variacão & Variância $(8)$ & teste F \\
\hline Amostragem & 7,0 & 1,47 \\
Quarteação:am & 42,0 & $3,59^{\text {kt }}$ \\
Preparo:q:am & 13,7 & 1,74 \\
Determinação:p:q:am & 37,3 & \\
\hline Total & 100,0 & \\
\hline
\end{tabular}

Coeficiente de variação $=4,078$

Observou-se efeito estatisticamente significativo da etapa de amostragem nos resultados de nitrogênio e fósforo, mas não para o potássio. Os resultados apresentados anteriormente podem indicar que a diferenciação de composição em fósforo dos sacos de fertilizantes, foi a responsável pelo efeito da amostragem nos resultados desse nutriente. Por outro lado, a homogeneidade de tamanho de particulas da fonte fosfatada, não causou problema de seqreqação durante as etapas de quarteação, concordando com SILVA (1984).

Em relação ao potássio, a influência apenas do processo de quarteacão revela que a qualidade de trabalho nesta etapa foi bastante afetada pelas características do produto, induzindo uma variabilidade nos resultados analiticos maior que aquela resultante de uma possivel variacão de composicão entre os sacos. o fato da quarteação de laboratório não mostrar interferência, tanto para fósforo como para potássio, se justifica desde que esta etapa transcorre sob condiçoses mais controladas que a 
mesma etapa no campo.

Quanto ao nitrogênio também a diversidade de composição de sacos deve ter resultado no efeito significativo do processo de amostragem. A influência do processo de quarteação em laboratório para este nutriente é dificil de ser explicada, visto que a quarteação de campo não manifestou efeito.

o efeito da determinação analítica, avaliado pela porcentagem da contribuição desta etapa para a variância total, manifestou-se em maior grau para nitrogênio $(45,18)$ e potássio (37.38), do que para fósforo, revelando que o método gravimétrico do fosfomolibdato de quinolina é superior em precisão ao método volumétrico, empregado para o nitrogênio e ao método fotométrico de chama. Os métodos gravimétricos realmente apresentam elevada precisão, sendo por isso considerados métodos de referência, mas sua utilização rotineira sofre restrições por serem demorados e trabalhosos.

Além dos resultados das determinações de nitrogênio, fósforo e potássio, a soma dos teores desses nutrientes também é avaliada como fator de qualidade no processo de fiscalização de fertilizantes. o estudo de composição de variância também foi aplicado à soma de nutrientes da mistura 4-14-8, indicando que 43,138 da variância total da soma foi devido à determinação analítica, enquanto que valores de 41,468 e 15,418 foram encontrados para a amostragem e quarteação no campo, respectivamente. A contribuição da quarteação efetuada no laboratório foi considerada nula. 
4.2. Variabilidade na determinação de nitrogênio, fósforo e potássio em função dos laboratórios e dos método analíticos.

Discute-se neste item os resultados das análises estatísticas referentes ao confronto dos resultados médios obtidos pelos seis laboratórios, para todas as amostras, considerando cada método analitico individualmente. Desde modo, cada método analítico compreende um conjunto de dados específico e diferenciado.

Apresenta-se também a comparação entre métodos analiticos, selecionando-se as amostras e os laboratórios que tinham determinado os nutrientes por todos os métodos envolvidos.

4.2.1. Determinação de nitrogênio total

Conforme o apresentado na Tabela 14, não houve efeito significativo para o fator laboratório, ao nível de 18 de probabilidade, para qualquer um dos três métodos estudados. Este fato pode ser explicado pela experiência dos técnicos dos laboratórios na execução dos métodos, e pela precisão e exatidão dos métodos considerados.

Os resultados permitem concluir também, que a simplificação proposta por ALCARDE (1982), além de tornar a análise mais rápida e econômica, não compromete a precisão e exatidão do método. 
Tabela 14. Comparação entre laboratórios na determinação de nitrogênio total pelos métodos oficiais da liga de Raney e do ácido salicílico e método simplificado.

\begin{tabular}{cccc}
\hline Laboratório & & \multicolumn{3}{c}{ ó Nitrogênio total } \\
liga de Raney & simplificado \\
\hline L1 & ác. salic. & $18,36^{\mathrm{a}}$ & $18,10^{\mathrm{a}}$ \\
L2 & $18,31^{\mathrm{a}}$ & $18,20^{\mathrm{a}}$ & $18,15^{\mathrm{a}}$ \\
L3 & $18,31^{\mathrm{a}}$ & $18,21^{\mathrm{a}}$ & $17,94^{\mathrm{a}}$ \\
L4 & $18,24^{\mathrm{a}}$ & $18,24^{\mathrm{a}}$ & $18,06^{\mathrm{a}}$ \\
L5 & $18,09^{\mathrm{a}}$ & $18,10^{\mathrm{a}}$ & $18,16^{\mathrm{a}}$ \\
L6 & $18,07^{\mathrm{a}}$ & $17,90^{\mathrm{a}}$ & $17,78^{\mathrm{a}}$ \\
\hline média & $17,88^{\mathrm{a}}$ & & \\
teste F & 18,15 & 18,17 & 18,03 \\
prob. $>$ F & 1,46 & 1,09 & 1,39 \\
CVo & 0,21 & 0,37 & 0,24 \\
\hline
\end{tabular}

médias seguidas de mesma letra não diferem ao nível de 18 de probabilidade pelo teste de Tukey.

A comparação entre os resultados analiticos de nitrogênio total obtidos pelos métodos oficiais de liga de Raney e do ácido salicilico e pelo método simplificado é mostrado na Figura 6. o coeficiente de determinação da regressão linear mostra que os dados estão perfeitamente correlacionados, e pela aplicação do teste $t$ pode-se afirmar com 18 de probabilidade que não existe diferença significativa entre os métodos estudados, não se manifestando erros proporcionais ou aditivos significativos do ponto de vista estatistico. 

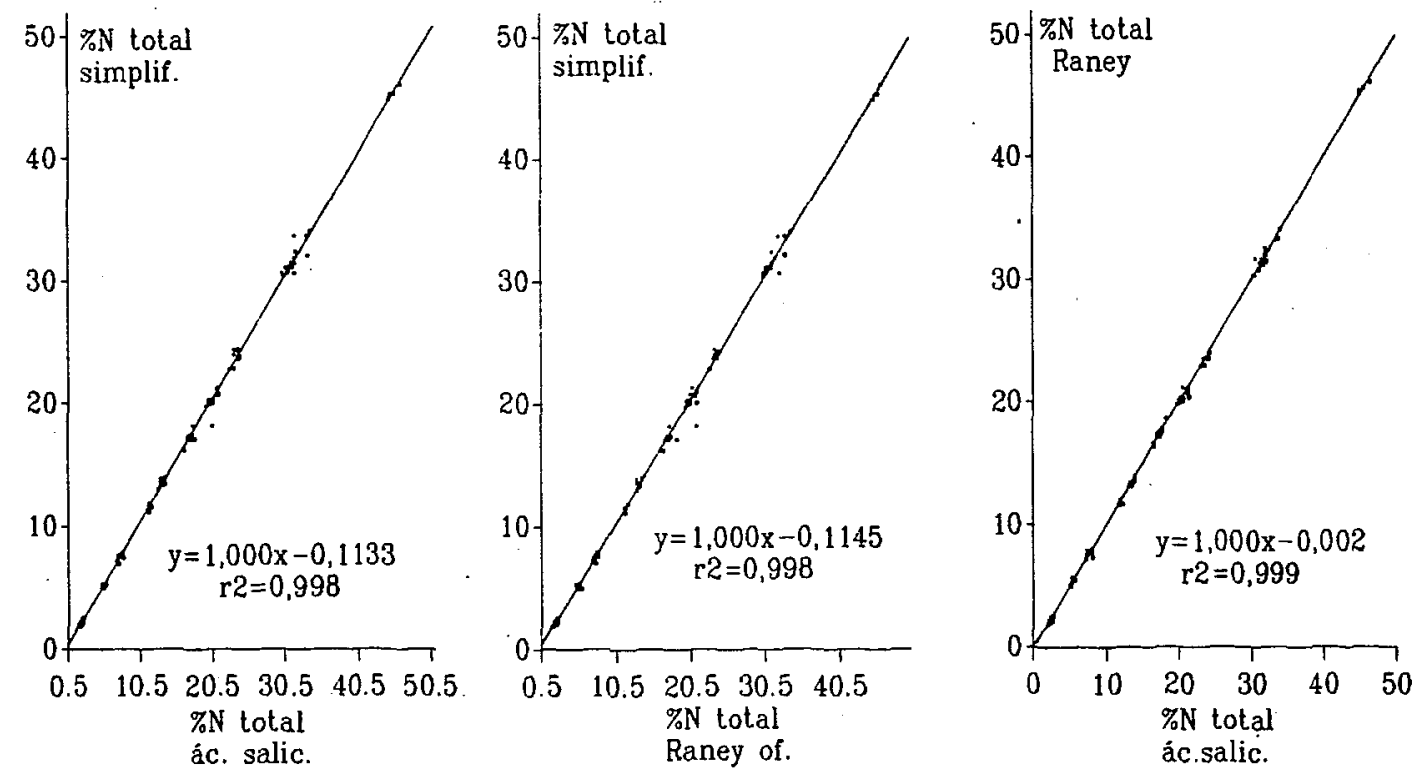

Figura 6. Relação entre teores de nitrogênio total em fertilizantes determinados pelos métodos oficiais da liga de Raney e do ácido salicilico e pelo método simplificado

\subsubsection{Determinação de fósforo}

Considerando-se primeiramente a determinação de fósforo pelo método oficial gravimétrico, conforme se pode observar na Tabela 15, não foi detectado efeito significativo para o fator laboratório nas determinações de fósforo total e de fosforo solúvel em água, enquanto que para o fósforo solúvel em CNA+água, ocorreu efeito altamente significativo ao nivel de 18 de probabilidade.

A diferença de comportamento entre laboratórios na a determinação da forma solúvel em CNA+água, reflete a dificuldade de padronização das condições de extração: temperatura, tempo e velocidade de agitação. Para a forma solúvel em água essa restrição é menos acentuada, e a diferença entre laboratórios só é estatisticamente siqnificativa a nivel superior a $5 \%$. No caso da forma fósforo total, o processo de extração é drástico, pratica- 
mente não oferecendo margem a diferenças entre os laboratórios.

Tabela 15. Comparação entre laboratórios na determinação de fósforo total, solúvel em água e solúvel em solução neutra de citrato de amônio mais água(CNAtágua).

\begin{tabular}{|c|c|c|c|c|c|c|}
\hline \multirow{2}{*}{$\begin{array}{l}\begin{array}{l}\text { labora- } \\
\text { tório }\end{array} \\
\text { L1 }\end{array}$} & $\begin{array}{r}\mathrm{P}_{2} \mathrm{O}_{5} \\
\text { oficial }\end{array}$ & $\begin{array}{l}\text { total } \\
\text { simplif. }\end{array}$ & \multicolumn{2}{|c|}{$\mathrm{P}_{2} \mathrm{O}_{5}$ água } & \multicolumn{2}{|c|}{$\mathrm{P}_{2} \mathrm{O}_{5} \mathrm{CNA}+a ́ g u a$} \\
\hline & $29,82^{a}$ & -- & $22,77^{a}$ & -- & $20,57^{a b}$ & $21,19^{a b}$ \\
\hline L2 & $29,92^{a}$ & $29,73^{b}$ & $22,90^{\mathrm{a}}$ & $23,18^{\mathrm{AB}}$ & $20,34^{b}$ & $21,01^{b}$ \\
\hline L3 & $30,02^{a}$ & $29,34^{b}$ & $23,08^{a}$ & $23,24^{\mathrm{AB}}$ & $20,59^{a b}$ & $20,68^{b}$ \\
\hline L4 & $30,16^{a}$ & $30,71^{a}$ & $23,32^{a}$ & $23,72^{\AA}$ & $21,01^{a}$ & $21,65^{\mathrm{a}}$ \\
\hline L 5 & $30,12^{a}$ & $30,20^{\mathrm{ab}}$ & $23,06^{a}$ & $23,61^{A}$ & $20,53^{a b}$ & $21,16^{\mathrm{ab}}$ \\
\hline L6 & $29,90^{a}$ & $29,90^{b}$ & $22,68^{\mathrm{a}}$ & $22,29^{8}$ & $20,78^{a b}$ & $21 \cdot 25^{a b}$ \\
\hline média & 29,99 & 29,98 & 22,97 & 23,21 & 20,63 & 21,16 \\
\hline \multicolumn{3}{|l|}{ teste F } & 2,23 & 3,08 & 4,80 & 6,68 \\
\hline \multicolumn{7}{|l|}{ prob. $>F$} \\
\hline & 0,548 & 0,001 & 0,068 & 0,033 & 0,001 & 0,001 \\
\hline $\mathrm{CV}$ 웅 & 1,01 & 0,92 & 1,96 & 3,52 & 2,51 & 2,48 \\
\hline
\end{tabular}

médias seguidas de letras distintas diferem entre si pelo teste de Tukey: letras maiúsculas ao nivel de 58 , minúsculas a 18 de probabilidade.

Houve diferença estatisticamente significativa entre laboratórios, quando os resultados foram obtidos pelo método simplificado, independentemente da forma de fósforo considerada, evidenciando que o método oficial gravimétrico ofereceu maior precisão. Esse fato pode demonstrar uma relativa inexperiência dos laboratórios oficiais com os métodos colorimétricos, mais habituados a trabalhar com os métodos por gravimetria exigidos na análises de fiscalização. 

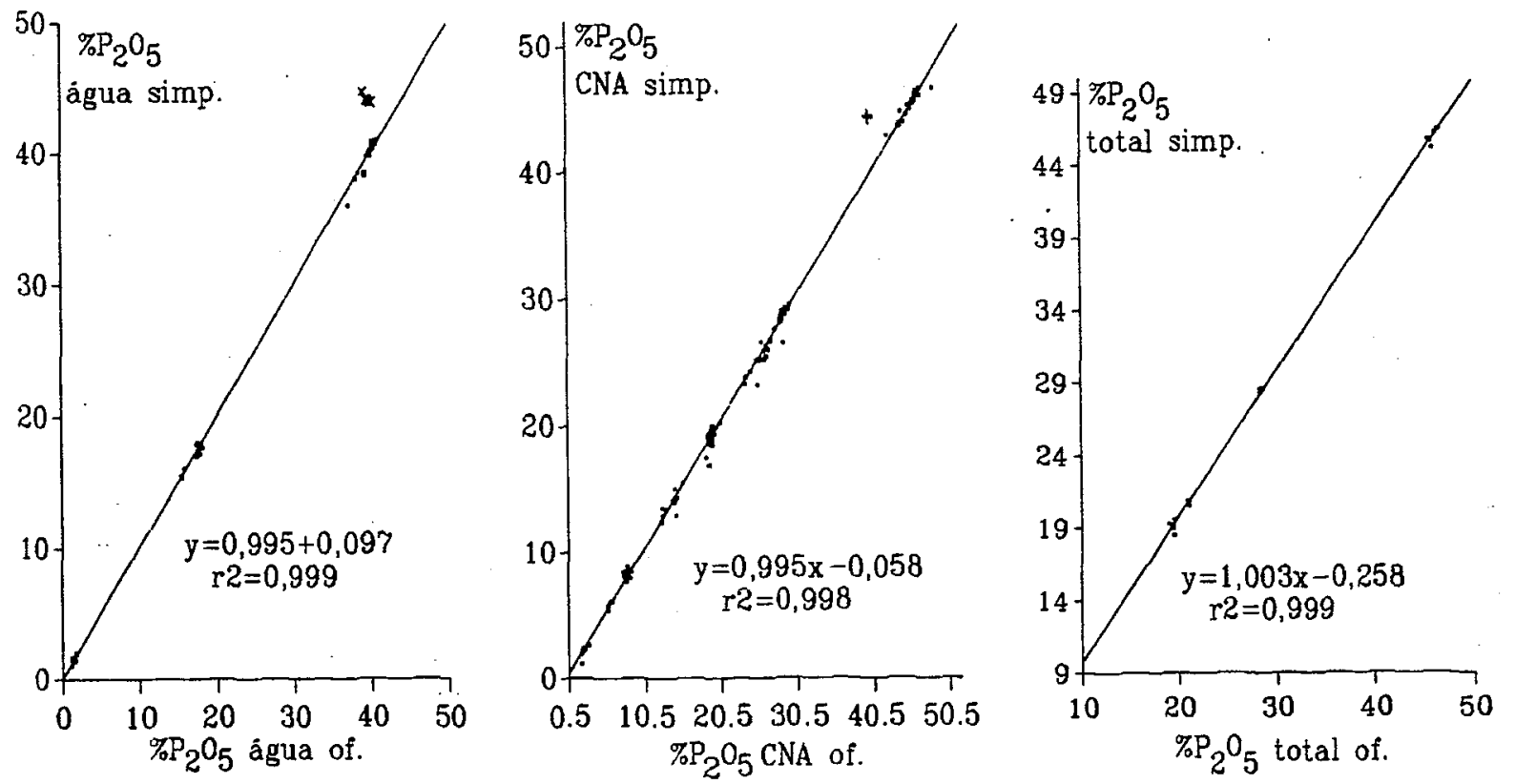

Figura 7. Relação entre teores de fósforo total, fósforo solúvel em água e fósforo solúvel em solução neutra de citrato de amônio mais água, determina dos pelos respectivos métodos oficiais e simplificados.

Na figura 7 são mostradas as representações gráficas das correlaçōes dos resultados de determinação de fósforo total, solúvel em água e solúvel em CNAtágua, pelos métodos oficiais e simplificados. Foram observados valores elevados de coeficiente de determinação e não ficou evidenciada a ocorrência de diferencas aditivas ou proporcionais, estatisticamente significativas, empregando-se o teste $t$. 


\subsubsection{Determinação de potássio}

Conforme o apresentado na Tabela 16 , não houve efeito significativo para o fator laboratório, para qualquer um dos três métodos estudados.

Os métodos fotométricos de chama oficial e simplificado são praticamente idênticos, diferindo apenas quanto à calibração. Não houve diferenças entre laboratórios, apesar do procedimento analitico exigir diluiçoses elevadas e de se operar com um instrumento, cuja calibração pode ser por vezes apresentar dificuldades para ser ajustada.

Já o método oficial TFBS é um método volumétrico, que na época era mais difundido entre os laboratórios oficiais que o método instrumental de chama. A concordância dos seus resultados entre os laboratórios pode ser justificada pelo fato de, apesar de ser trabalhoso, permite atingir um elevado nível de precisão.

No confronto entre métodos de determinação de potássio, pode-se admitir uma tendência dos resultados pelo método fotométrico de chama simplificado serem mais baixos que os obtidos pelo mesmo método em sua versão oficial. Essa diferença foi de $0,19 \$ \mathrm{~K}_{2} \mathrm{O}$, em unidades percentuais, conforme indica 0 coeficiente linear da regressão, que foi estatisticamente diferente de zero ao nivel de 108 de probabilidade, indicado pelo teste $t$. Essa tendência de resultados mais baixos para o método de fotometria de chama em relação ao método do tetrafenilborato de sódio, também foram encontrados por ALCARDE \& BORELLA (1976). 
Tabela 16. Comparação entre laboratórios na determinação de potássio pelo método oficial do tetrafenilborato de sodio (TFBS) e método fotométrico de chama, nas versōes oficial e simplificada.

\begin{tabular}{lccc}
\hline Laboratório & TFBS & $\begin{array}{c}\text { o Potásio } \\
\text { F.chama ofic }\end{array}$ & F.chama simpl. \\
\hline L1 & $19,57^{\mathrm{a}}$ & -- & $17,14^{\mathrm{a}}$ \\
L2 & $19,53^{\mathrm{a}}$ & $19,46^{\mathrm{a}}$ & $17,11^{\mathrm{a}}$ \\
L3 & $19,86^{\mathrm{a}}$ & -- & -- \\
L4 & $19,48^{\mathrm{a}}$ & $19,82^{\mathrm{a}}$ & $17,39^{\mathrm{a}}$ \\
L5 & $19,78^{\mathrm{a}}$ & $19,65^{\mathrm{a}}$ & $17,30^{\mathrm{a}}$ \\
L6 & $20,06^{\mathrm{a}}$ & -- & $17,60^{\mathrm{a}}$ \\
\hline & 19,72 & 19,64 & 17,31 \\
média & 0,92 & 2,06 & 0,72 \\
teste F & 0,53 & 0,14 & 0,59 \\
prob. $>\mathrm{F}$ & 4,21 & 2,57 & 4,00 \\
CVo & & &
\end{tabular}

médias seguidas de mesma letra não diferem ao nível de 18 de probabilida- de pelo teste de Tukey.

Quando foram comparados os métodos fotométrico de chama simplificado com o método oficial TFBS observou-se tendência de manisfestação de diferenças proporcionais e aditivas ao nivel de 108 de probabilidade. Desta forma, os resultados do método simplificado tenderam a ser em média 1,18 maiores que o do método oficial, mas a diferença aditiva torna-os menores em 0,29 unidades percentuais, conforme indica a equaçāo de regressão mostrada na Figura 8 . 

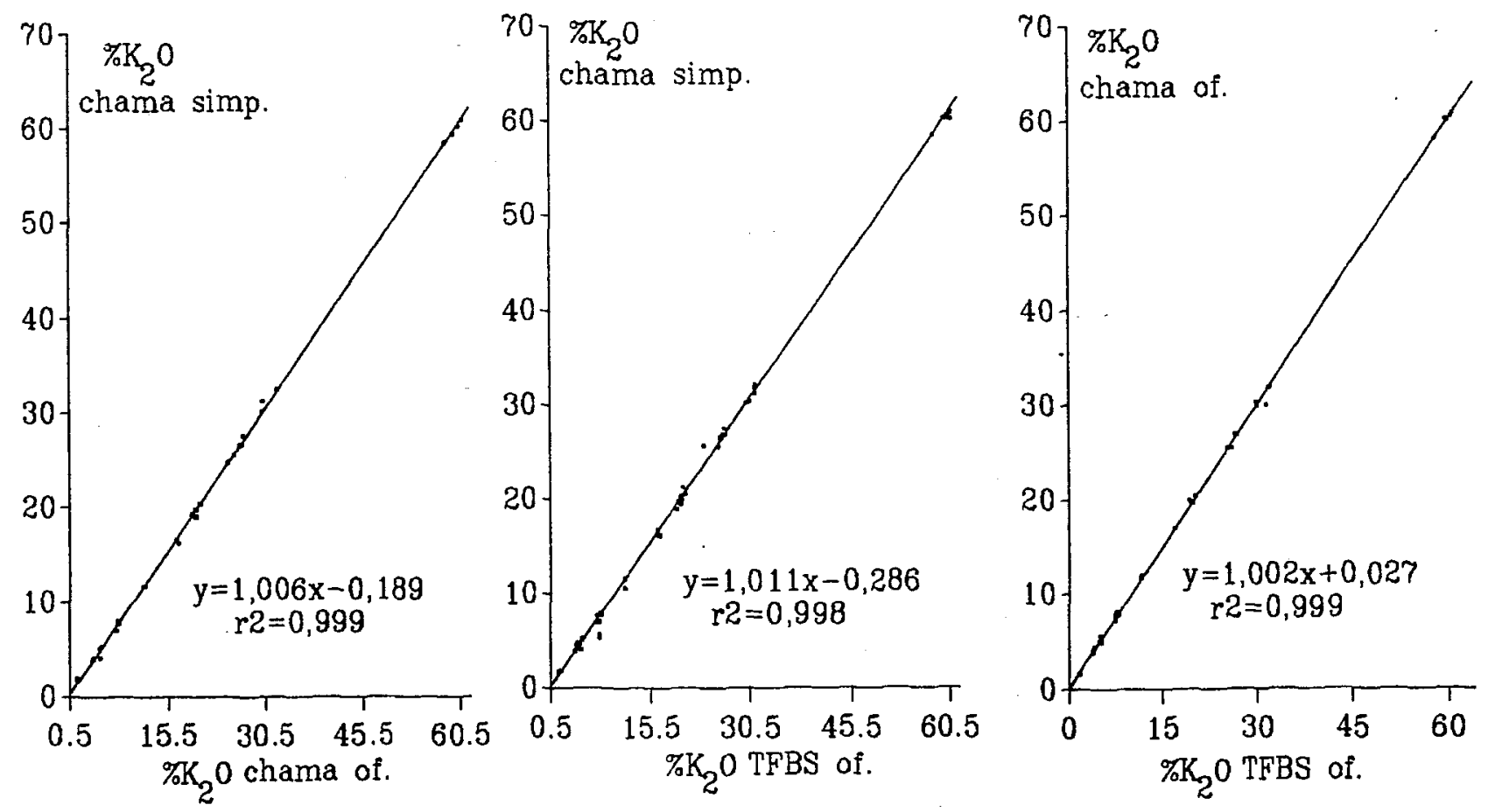

Figura 8. Relação entre teores de potássio em fertilizantes determinados pelos métodos oficiais, fotométrico chama e tetrafenilborato de sódio (TFBS), e método fotométrico de chama simplificado. 


\section{CONCLUSŌES}

Nas condições que prevaleceram no presente estudo as seguintes conclusões puderam ser estabelecidas:

o modelo estatístico de classificação hierárquica evidenciou a contribuição diferenciada de cada etapa da análise de fertilizantes para a variância total dos teores de nitrogênio, fósforo e potássio em misturas de grânulos.

A coleta de fertilizantes nos sacos e a redução da amostra por quarteação também afetaram a massa das amostras selecionadas para análise.

Ocorreu ampla variação de composição química da mistura de grânulos em função da fração granulométrica considerada.

As etapas de amostragem e redução da amostra por quarteação afetaram a precisão dos resultados da análise granulométrica das frações extremas $(>4,00 \mathrm{~mm} \theta<0,5 \mathrm{~mm}$ ).

A metodologia oficial de coleta de amostra para análise fiscal de fertilizantes é precisa, produzindo amostras representativas.

Quando se comparou diferentes laboratórios, as maiores diferenças entre resultados de análise ocorreram na determinação de fósforo solúvel em solução neutra de citrato de amônio mais água.

A metodologia simplificada de análise de fertilizantes produziu resultados que não diferiram dos obtidos pelos métodos oficiais. 


\section{REFERENCIAS BIBLIOGRAF ICAS}

ALCARDE, J.C. Métodos simplificados de análise de fertilizantes (N, P, K) minerais. Brasilia, Laboratório Nacional de Referência Vegetal, 1982. 49p.

ALCARDE, J.C. Simplificaçao na metodologia (NPK) de fertilizantes minerais. Piracicaba, 1991. 115p. (Livre-docência-Escola Superior de Agricultura "Luiz de Queiroz"/USP).

ALCARDE, J.C. Qualidade de fertilizantes e corretivos. In:REUNIÃO BRASILEIRA DE FERTILIDADE DO SOLO E NUTRIÇÃO DE PLANTAS, 20., Piracicaba, 1992. Anais. Campinas, Fundação Cargill, 1992. p.275-98.

ALCARDE, J.C. A físico-química, a química analftica e a qualidade de fertilizantes minerais. Piracicaba, ESALQ/ Departamento de Química, 1994. 43p.

ALCARDE, J.C. \& BORELLA, J.E. Determinação do potássio em fertilizantes por fotometria de chama de emissão. Anais da Escola Superior de Agricultura "Luiz de Queiros", Piracicaba, 33: $726-51,1976$.

ALCARDE, J.C. \& PAULINo, J.T. Avaliação do método modificado da liga de Raney de determinação do nitrogênio total em fertilizantes, Revista Brasileira de Ciência do Solo, Campinas, 8: $151-3,1984$.

ALCARDE, J.C.; GUIDOLIM, J.A.; LOPES, A.S. Os adubos e a eficiência das adubaçōes. São Paulo, ANDA, 1989. 35p. (ANDA. Boletim Técnico, 3). 
ASSOCIAÇAO NACIONAL PARA DIFUSÃo DE ADUBOS E CORRETÍVOS AGRTCOLAS. Anuário estatístico do setor de fertilizante. São Paulo, 1986-93.

BALASTREIRE, L.A. \& COELHO, J.L.D. Aplicação mecanizada de fertilizantes e corretivos. São Paulo, ANDA, 1992. 47p. (ANDA. Boletim técnico, 7).

BARBIN, D. Componentes da variância. Piracicaba, ESALQ/ Depto. de Matemática e Estatística, 1993. 109p.

BRASIL. Ministério da Agricultura. Divisão de Corretivos e Fertilizantes. Inspeçāo e fiscalização da produção e do comércio de fertilizantes, corretivos, inoculantes, estimulantes ou biofertilizantes destinados à agricultura; legislação. Brasi$1 \mathrm{ia}, 1983 \mathrm{a} .88 \mathrm{p}$.

BRASIL. Ministério da Agricultura. Laboratório Nacional de Referência Vegetal. Análise de corretivos, fertilizantes e inoculantes; métodos oficiais. Brasilia, 1983b. $104 \mathrm{p}$.

BRUNO, M.A.C. Processos de fabricação de produtos fertilizantes. In: coord. Conservação de energia na indústria de fertilizantes. São Paulo, IPT, 1985. cap.3, p.35-93. (Publicação IPT, 1632).

ESTADOS UNIDOS. Department of state Agency for International Development, Office of Smal1 Business. A.I.D. fertilizer spe-cifications; small businees. Washington, 1977. (USAID. Memo, $77-3)$. 
FERREIRA， C.R.R.P.T. Mercado de insumos e máquinas agrícolas. Informaçōes Econômicas, São Paulo, 23(7):73-4, 1993.

FERREIRA， C.R.R.P.T. Mercado de insumos e máquinas agrícolas. Informações Econômicas, São Paulo, 24(11):54, 1994 .

GEHRKE, C.W. Sampling bagged fertilizers. Journal of the American Official Analysis Chemistry, Washington, 55(4):709, 1972.

GOSSELIN, J. A. What is happening to quality control in blending? (producer). In: ANNUAL MEETING OF THE FERTILIZER INDUSTRY ROUND TABLE, 33., Glen Arm, 1983. Proceedings. Maumee, Andersons, 1983. p.39-40.

HANCOCK, M.R. What is happening to quality control in blending? In: ANNUAL MEETING OF THE FERTILIZER INDUSTRY ROUND TABLE, 33., Glen Arm, 1983. Proceedings. Maumee, Andersons, 1983. p. $32-4$.

HAUSER, G.F. The calibration of soil tests for fertilizer recomendation. Rome, FAO, 1973. 71p.

HOFFMEISTER, G. Compatibility of raw materials. In: ANNUAL MEETING OF THE FERTILIZER INDUSTRY ROUND TABLE, 12., Washing ton, 1962. Proceedings. Maumee, Andersons, 1962. p.82-3.

HOFFMEISTER, G. Quality control in a bulk blending plant. In: TVA FERTILIZER BULK BLENDING CONFERENCE, Muscle Shoals, 1973. Proceedings. Muscle Shoals, Tennessee Valley Authority, 1973. p.59-70. (TVA Bulletin, Y-62). 
HOFFMEISTER, G. Designing bulk blend plants to reduce segregation. In: ANNUAL MEETING OF THE FERTILIZER INDUSTRY ROUND TABLE, 26., Atlanta, 1976. Proceedings. Maumee, Andersons, 1976. p. 67-75.

HOFFMEISTER, G. Physical properties of fertilizers and methods for measuring them. Muscle Shoals, Tennessee Valley Authority, 1979. 31p. (TVA Bulletin, 147).

HOFFMEISTER, G. \& MEGAR, G.H. Use of urea in bulk blends. In: ANNUAL MEETING OF THE FERTILIZER INDUSTRY ROUND TABLE, 25., Washington, 1975. Proceedings. Maumee, Andersons, 1975. p. 212-26.

HOFFMEISTER， G.; WATKINS， S.C.; SILVERBERG，J. Bulk blend of fertilizer material: effect of size, shape, and density on segregation. Journal of Agricultural and Food Chemistry, Easton, 12(1):64-9, 1964 .

HUBER JUNIOR, E.J. Effects of awhysical properties of dry fertilizers upon sampling and chemical analysis. In: SAMPLING AND ANALYSIS OF FERTILIZERS SYMPOSIUM, Washington, 1984. Sampling and analysis of fertilizers. Arlington, Association of Official Chemists; Baltimore, Agr. Chemical, 1985. p.52-7.

JOHNSON, F.J.; WOODIS Jr., T.C.; CUMMINGS Jr., J.M. Mercury free Raney catalysis method for total nitrogen in fertilizers. Journal of the American Official Analysis Chemistry, Washington, $57(1): 10-3,1974$.

KUMMER, K.F. "Bulk blending" no es alternativa alguna para fertilizantes complejos NPK!. BASF Reportes Agricolas, Limburgerhof, 3:14-7, 1989 . 
MALAVOLTA, E. Controle de qualidade de fertilizantes. São Paulo, ANDA, 1978 . 39p.

MALAVOLTA, E. Manual de química agrícola; adubos e adubaçōes. 3.ed. São Paulo, Ceres, 1981. 549p.

PETTYGROVE, "G.S. \& SCHENEIDER, P.S. Sampling variances of bulkblended dry fertilizers. Journal of the American official Analysis Chemistry, Washington, 62(4):728-32, 1979.

POPP, T. \& ULLRICH, K.H. La importancia de la calidad del fertilizante para la aplicación con fertilizadoras. BASF Reportes Agricolas, Limburgerhof, 2:3-13, $1985 \mathrm{a}$.

POPP, T. \& ULLRICH, K.H. Diversos tipos de fertilizantes compuestos $y$ su calidad. BASF Reportes Agricolas, Limburgerhof, $3: 14-23,1985 b$.

PRESSINOTTI, A.F. Propriedades físicas dos fertilizantes. In: CURSO SOBRE INSPEÇ̃̃o B FISCALIZAÇÃO DE FERTILIZANTES, São Paulo, 1984. São Paulo, IPT, 1984. p.irreg.

PROCHNOW, L.I.; VITTI, G.C.; PEREIRA, H.S.; FERREIRA, A.C. Levantamento da situação dos laboratórios de análise de plantas no Brasil. Boletim Informativo da Sociedade Brasileira de Ciência do Solo, Campinas, 19(2):47-52, 1994 .

QUACKENBUSH, F.W.; RUND, R.C.; MILES, J.R. Laboratory variations in the analysis of fertilizers. Journal of the American official Analysis Chemistry, Washington, 49(5): 915-43, 1966. 
QUACKENBUSH, F.W. \& RUND, R.C. The continuing problem of sampling. Journal of the American Official Analysis Chemistry, Washington, 50(5):997-1006, 1967.

RAIJ, B. van; CANTARELLA, H.; QUAGgIO, J.A. Soil testing and plant analysis in Brazil. Communications in Soil science and Plant Analysis, New York, 25(7/8):739-51, 1994.

RAIJ, B. van; GUAGgio, J.A.; CANTARELla, H.; FERREIRA, M.E.; BATAGLIA, O.C. Análise química do solo para fins de fertilidade. Campinas, Fundação Cargil1, 1987. 170p.

RODELLA, A.A. \& ALCARDE, J.C. Variabilidade na composição de misturas fertilizantes decorrente de segregação e estimativa do efeito sobre a produtividade da cana-de-açucar. STAB Açúcar e Alcoo1, Piracicaba, 13(2):14-9, 1994.

RODELLA, A.A. \& BORGES, M.T.M.R. Manual básico para o laboratório sucro-alcooleiro. Piracicaba, Degaspari, 1989. 225p.

ROGERS, H.V. Fertilizer quality control - can it be achieved in today's marketing system. In: ANNUAL MEETING OF THE FERTILIZER INDUSTRY ROUND TABLE, 33., Glen Arm, 1983. Proceedings. Maumee, Andersons, 1983. p.23-6.

SILVA, G.A. Controle de qualidade. In: CuRso sobre INSPEÇão B PISCALIZAÇ̃̃o DE FERTILIZANTES, São Paulo, 1984. São Paulo, IPT, 1984. p. irreg.

SILVEIRA, P.B.M. Granulação e mistura de fertilizantes. In: INSTituto de pesquisas tecnológicas. Tecnologia de produção de fertilizantes. São Paulo, IPT, 1990. p.145-62. 
SILVERBERG, J.; LEHR, J.R.; HOFFMEISTER, G. Microscopy study of the mechanism of caking and its prevention in some granular fertilizers. Journal of Agricultural and Food Chemistry, Easton, $6(6): 442-8,1958$.

SILVERBERG, J.; YOUNG, R.D.; HOFFMEISTER, G. Preparation of fertilizers containing micronutrients. In: DINAUER, R.C., ed. Micronutrients in agriculture. Madison, soil science Society of America, 1972. p.431-58.

SMITH, G.E. Bulk blended. In: ANNUAL MEETING OF THE FERTILIZER INDUSTRY ROUND TABLE, 11., Washington, 1960. Proceedings. Maumee, Andersons, 1960. p.90-7.

TAYLOE, R. Chemical control in the fertilizer plant. In: SAUCHELLI, V., ed. Manual on fertilizer manufacture. Caldweel, Industry Publ, 1963. p.356-68.

TERRY, D.L. What is happening to quality control in blending? (control official). In: ANNUAL MEETING OF THE FERTILIZER INDUSTRY ROUND TABLE, 33., Glen Arm, 1983. Proceedings. Maumee, Andersons, 1983. p.27-8.

TERRY,D.L.; NELSON,L.; STEVENS, J.; CAINE, D.; JOHNSON, F.; HUBER, E.J.; HANCOCK, M.R. Variance and representativeness of the A.O.A.C. sampling procedure for bagged fertilizer. Journal of the American Official Analysis Chemistry, Washington, $74(2): 332-40,1991$.

VERNE, H.G. Sampling and meeting legal guarantees. In: ANNUAL MEETING OF THE FERTILIZER INDUSTRY ROUND TABLE, 28. , Atlanta, 1978. Proceedings. Maumee, Andersons, 1978. 
VITTI, G.C.; PEREIRA, H.S.; PERECIN, D.; FERRAUDO,A.S. Programa de controle de qualidade de laboratórios de análise foliar (ano 6 .1991/1992). Boletim Informativo da Sociedade Brasileira de Ciência do Solo, Campinas, 17(2): 52-6, 1992.

WATLEY, W.D. A review of quality control in granulation plants. In: ANNUAL MEETING OF THE FERTILIZER INDUSTRY ROUND TABLE, 28., Atlanta, 1978. Proceedings. Maumee, Andersons, 1978 .

WOODIS, T.C.; HOMES, J.H.; HUNTER, G.B.; JOHSON, F.J. Evalutation of two-way riffes for precise division of blended fertilizer. Journal of the American Official Analysis Chemistry, Washington, 62(4):733-7, 1979.

YOUDEN, W.J. Techinique for testing the accuracy of analitical data. Analytical Chemistry, Washington, 19:94-6, 1947. 


\section{APENDICE}

Neste apêndice estão apresentados os valores das determinações analiticas efetuadas para todas as amostras incluidas no programa interlaboratorial estudado, bem como os resultados analiticos utilizados no estudo de composição de variância envolvendo a mistura de grânulos 4-14-8. 
Material: Mistura de grânulos

\begin{tabular}{|c|c|c|c|c|c|c|c|c|}
\hline $\begin{array}{c}\text { Amost } \\
01\end{array}$ & \multicolumn{3}{|c|}{$8 \mathrm{~g}$} & \multicolumn{2}{|c|}{$\begin{array}{c}{ }^{8} \mathrm{P}_{2} \mathrm{O}_{5} \\
\text { cnatagua }\end{array}$} & \multicolumn{3}{|c|}{$8 \mathrm{~K}_{2} \mathrm{O}$} \\
\hline Labor & Salic & Raney & Simpl & Ofic. & Simpl & TFBS & Fot.ch & simpl \\
\hline L1 & 2,6 & 2,6 & 2,6 & 19,3 & 18,9 & 23,6 & & 25,7 \\
\hline L 2 & 2,3 & 2,5 & 2,5 & 19,4 & 19,6 & 26,3 & 26,5 & 26,6 \\
\hline L3 & 2,2 & & 2,1 & 19,6 & 19,5 & 27,3 & & \\
\hline L 4 & & & & & & & & \\
\hline L5 & 2,0 & 2,1 & 2,1 & 19,4 & 19,2 & & 26,8 & 26,7 \\
\hline L6 & 1,9 & 1,9 & 1,9 & 19,6 & 19,5 & 26,9 & & 26,9 \\
\hline $\bar{X}$ & 2,19 & 2,27 & 2,25 & 19,46 & 19,33 & 26,02 & 26,65 & 26,47 \\
\hline STD & 0,26 & 0,33 & 0,28 & 0,13 & 0,30 & 1,68 & 0,21 & 0,54 \\
\hline CV 8 & 11,6 & 14,4 & 12,40 & 0,69 & 1,55 & 6,47 & 0,80 & 2,03 \\
\hline
\end{tabular}

Material: Mistura de grânulos

\begin{tabular}{|c|c|c|c|c|c|c|c|c|}
\hline $\begin{array}{c}\text { Amost } \\
\text { O2 }\end{array}$ & \multicolumn{3}{|c}{$8 \mathrm{~N}$} & \multicolumn{2}{c|}{$\begin{array}{c}8 \mathrm{P}_{2} \mathrm{O}_{5} \\
\text { Cna+agua }\end{array}$} & \multicolumn{3}{c|}{$8 \mathrm{~K}_{2} \mathrm{O}$} \\
\hline Labor & Salic & Raney & Simp1 & Ofic. & Simpl & TFBS & Fot.ch & simp1 \\
\hline L1 & 7,9 & 7,8 & 7,8 & 28,6 & 29,1 & 5,2 & & 5,3 \\
L2 & 7,9 & 7,8 & 7,9 & 28,4 & 28,7 & 5,3 & 5,0 & \\
L3 & 7,8 & & 7,7 & 29,0 & 28,8 & 6,2 & & 5,1 \\
L4 & 7,3 & 7,9 & 7,6 & 29,6 & 29,6 & 5,1 & 5,0 & 5,1 \\
L5 & 7,5 & 7,7 & 7,7 & 28,6 & 29,0 & & 5,3 & 5,3 \\
L6 & 7,9 & 8,0 & 7,8 & 29,1 & 29,3 & 5,7 & & \\
\hline X & 7,72 & 7,84 & 7,75 & 28,88 & 29,08 & 5,50 & 5,10 & 5,23 \\
STD & 0,26 & 0,11 & 0,11 & 0,44 & 0,33 & 0,45 & 0,17 & 0,12 \\
CV8 & 3,32 & 1,45 & 1,35 & 1,52 & 1,14 & 8,23 & 3,40 & 2,21 \\
\hline
\end{tabular}


Material: Mistura de grânulos

\begin{tabular}{|c|c|c|c|c|c|c|c|c|}
\hline \multirow{2}{*}{$\begin{array}{c}\begin{array}{c}\text { amost } \\
03\end{array} \\
\text { labor }\end{array}$} & \multicolumn{3}{|l|}{$8 \mathrm{~N}$} & \multicolumn{2}{|c|}{$\begin{array}{c}{ }_{8} \mathrm{P}_{2} \mathrm{O}_{5} \\
\text { cnatagua }\end{array}$} & \multicolumn{3}{|l|}{$8 \mathrm{~K}_{2} \mathrm{O}$} \\
\hline & salic & Raney & simpl & ofic. & simpl & TEBS & $\begin{array}{l}\text { Fot. } \\
\text { chama }\end{array}$ & simpl \\
\hline L1 & 13,7 & 13,6 & 13,5 & 7,9 & 8,2 & 31,4 & & 32,2 \\
\hline โ2 & 13,8 & 13,9 & 14,0 & 7,9 & 8,0 & 30,0 & 30,0 & 30,2 \\
\hline L 3 & 13,5 & & 13,3 & 8,3 & 8,2 & 31,3 & & \\
\hline L 4 & 13,7 & 13,6 & & 8,0 & 8,3 & 31,9 & 31,9 & \\
\hline L 5 & 13,8 & 13,7 & 13,5 & 8,4 & 8,4 & & 32,2 & 32,5 \\
\hline $\mathrm{L} 6$ & 13,0 & 13,2 & 13,0 & 8,7 & 8,5 & 31,4 & & 31,8 \\
\hline$x$ & 13,58 & 13,60 & 13,46 & 8,20 & 8,27 & 31,2 & 31,37 & 31,68 \\
\hline STD & 0,31 & 0,26 & 0,37 & 0,32 & 0,18 & 0,71 & 1,19 & 1,02 \\
\hline CV용 & 2,25 & 1,88 & 2,71 & 3,93 & 2,12 & 2,28 & 3,80 & 3,23 \\
\hline
\end{tabular}

Material: Mistura de grânulos

\begin{tabular}{|c|c|c|c|c|c|c|c|c|}
\hline \multirow{2}{*}{$\frac{\begin{array}{c}\text { amost } \\
04\end{array}}{\text { labor }}$} & \multicolumn{3}{|l|}{$8 N$} & \multicolumn{2}{|c|}{$\begin{array}{c}{ }^{8} \mathrm{P}_{2} \mathrm{O}_{5} \\
\text { cnatagua }\end{array}$} & \multicolumn{3}{|l|}{$8 \mathrm{~K}_{2} \mathrm{O}$} \\
\hline & salic & Raney & simpl & ofic. & simpl & TFBS & $\begin{array}{l}\text { Fot. } \\
\text { chama }\end{array}$ & simpl \\
\hline L1 & 20,5 & 21,2 & 20,1 & 14,6 & 12,9 & 20,4 & & 21,3 \\
\hline L 2 & 20,0 & 19,9 & 20,3 & 14,4 & 14,4 & 19,8 & 19,8 & 19,8 \\
\hline L 3 & 20,1 & & 20,4 & 14,6 & 14,3 & 20,7 & & \\
\hline L 4 & 20,5 & 20,2 & & 14,5 & 15,0 & 19,3 & 20,0 & \\
\hline L 5 & 20,1 & 20,3 & 20,0 & 14,7 & 14,3 & 20,2 & 20,5 & 20,4 \\
\hline L 6 & 21,0 & 20,9 & 20,7 & 15,5 & 15,5 & 20,8 & & 20,6 \\
\hline $\mathrm{X}$ & 20,37 & 20,50 & 20,30 & 14,72 & 14,40 & 20,2 & 20,10 & 20,53 \\
\hline STD & 0,38 & 0,53 & 0,27 & 0,40 & 0,88 & 0,57 & 0,36 & 0,62 \\
\hline CV8 & 1,86 & 2,60 & 1,35 & 2,70 & 6,09 & 2,82 & 1,79 & 3,01 \\
\hline
\end{tabular}


Material: Mistura de grânulos

\begin{tabular}{|c|c|c|c|c|c|c|c|c|}
\hline \multirow{2}{*}{$\frac{\begin{array}{c}\text { amost } \\
05\end{array}}{1 \mathrm{abor}}$} & \multicolumn{3}{|l|}{$8 \mathrm{~N}$} & \multicolumn{2}{|c|}{$\begin{array}{c}8 \mathrm{P}_{2} \mathrm{O}_{5} \\
\text { cnatagua }\end{array}$} & \multicolumn{3}{|l|}{$8 \mathrm{~K}_{2} \mathrm{O}$} \\
\hline & salic & Raney & simpl & ofic. & simpl & TFBS & $\begin{array}{l}\text { Fot. } \\
\text { chama }\end{array}$ & simpl \\
\hline L1 & 23,4 & 23,6 & 24,0 & 26,3 & 25,2 & 4,4 & & 4,8 \\
\hline L 2 & 24,0 & 23,6 & 24,4 & 26,4 & 26,3 & 4,1 & 4,1 & 4,0 \\
\hline L 3 & 23,7 & & 23,7 & 26,2 & & 4,3 & & \\
\hline ᄃ 4 & 24,4 & 24,3 & & 26,8 & 26,0 & 4,3 & 4,4 & \\
\hline L5 & 23,5 & 23,6 & 24,4 & 26,2 & 25,9 & & 3,9 & 3,9 \\
\hline L 6 & 24,2 & 24,0 & 23,8 & 25,3 & 25,2 & 4,7 & & 4,7 \\
\hline$x$ & 23,87 & 23,82 & 24,06 & 26,20 & 25,72 & 4,36 & 4,13 & 4,35 \\
\hline STD & 0,40 & 0,32 & 0,33 & 0,49 & 0,50 & 0,22 & 0,25 & 0,47 \\
\hline CV웅 & 1,67 & 1,34 & 1,36 & 1,89 & 1,93 & 5,03 & 6,09 & 10,70 \\
\hline
\end{tabular}

Material: Mistura de grânulos

\begin{tabular}{|c|c|c|c|c|c|c|c|c|}
\hline \multirow{2}{*}{$\frac{{ }_{06}^{\text {amost }}}{\text { labor }}$} & \multicolumn{3}{|l|}{$8 \mathrm{~N}$} & \multicolumn{2}{|c|}{$\begin{array}{c}{ }_{8} \mathrm{P}_{2} \mathrm{O}_{5} \\
\text { cnatagua } \\
\end{array}$} & \multicolumn{3}{|l|}{$8 \mathrm{~K}_{2} \mathrm{O}$} \\
\hline & salic & Raney & simpl & ofic. & simpl & TFBS & $\begin{array}{l}\text { Fot. } \\
\text { chama }\end{array}$ & simpl \\
\hline L1 & 31,9 & 32,6 & 30,7 & 2,3 & 2,4 & 7,8 & & 5,7 \\
\hline ц2 & 32,0 & 31,5 & 32,4 & 2,3 & 2,4 & 8,1 & 8,1 & 7,8 \\
\hline L 3 & 32,3 & & & 2,1 & & 8,1 & & \\
\hline $\mathrm{L} 4$ & 31,3 & 31,1 & & 2,6 & 2,4 & 7,5 & & 7.7 \\
\hline L5 & 31,0 & 30,8 & 30,8 & 2,2 & 2,1 & & 7,9 & 7,7 \\
\hline $\mathrm{L} 6$ & 31,9 & 32,0 & 31,9 & 2,5 & 2,3 & 8,0 & & 7,9 \\
\hline$x$ & 31,73 & 31,60 & 31,45 & 2,33 & 2,32 & 7,90 & 8,00 & 7,36 \\
\hline STD & 0,48 & 0.72 & 0,84 & 0,19 & 0,13 & 0.25 & 0,14 & 0,93 \\
\hline CV8 & 1,53 & 2,27 & 2,65 & 7,98 & 5,62 & 3,23 & 1,77 & 12,66 \\
\hline
\end{tabular}


Material: Mistura de grânulos

\begin{tabular}{|c|c|c|c|c|c|c|c|c|}
\hline \multirow{2}{*}{$\begin{array}{c}\begin{array}{c}\text { amost } \\
07\end{array} \\
\text { labor }\end{array}$} & \multicolumn{3}{|l|}{$8 \mathrm{~N}$} & \multicolumn{2}{|c|}{$\begin{array}{c}8 \mathrm{P}_{2} \mathrm{O}_{5} \\
\text { cnatagua }\end{array}$} & \multicolumn{3}{|l|}{$8 \mathrm{~K}_{2} \mathrm{O}$} \\
\hline & salic & Raney & simpl & ofic. & simpl & TFBS & $\begin{array}{l}\text { Fot. } \\
\text { chama }\end{array}$ & simpl \\
\hline L1 & 8,1 & 7,4 & 7,5 & 28,5 & 28,7 & 5,1 & & \\
\hline L 2 & 7,4 & 7,6 & 7,0 & 28,3 & 28,1 & 5,0 & 5,1 & 4,1 \\
\hline L3 & 7,3 & 7,5 & 7,2 & 28,7 & 26,5 & $0,0^{*}$ & & \\
\hline Ł 4 & 7,3 & 7,7 & 7,6 & 29,5 & 29,2 & 5,2 & 5,6 & \\
\hline L5 & 7,4 & 7,6 & 7,6 & 28,6 & 28,4 & & 5,1 & \\
\hline L 6 & 7,2 & 7,2 & 7,2 & 27,6 & 27,6 & 5,2 & & 5,2 \\
\hline$x$ & 7,45 & 7,50 & 7,35 & 28,53 & 28,08 & 4,10 & 5,27 & 4,65 \\
\hline STD & 0,33 & 0,18 & 0,25 & 0,62 & 0,95 & 2,29 & 0,29 & 0,78 \\
\hline $\mathrm{CV} 8$ & 4,39 & 2,39 & 3,42 & 2,16 & 3,37 & 55,94 & 5,48 & 16,73 \\
\hline
\end{tabular}

Material: Mistura de grânulos

\begin{tabular}{|l|l|l|l|l|l|l|l|l|}
\hline $\begin{array}{c}\text { amost } \\
08\end{array}$ & 8 $\mathrm{N}$ & \multicolumn{2}{c|}{$\begin{array}{c}8 \mathrm{P}_{2} \mathrm{O}_{5} \\
\text { cna+agua }\end{array}$} & \multicolumn{2}{l|}{$8 \mathrm{~K}_{2} \mathrm{O}$} \\
\hline labor & salic & Raney & simpl & of ic. & simpl & TFBS & $\begin{array}{l}\text { Fot. } \\
\text { chama }\end{array}$ & simpl \\
\hline L1 & 23,4 & 23,0 & 22,9 & 25,9 & 26,1 & 4,2 & & 4,6 \\
L2 & 24,1 & 23,5 & 23,7 & 26,4 & 25,4 & 4,1 & 3,9 & 3,9 \\
L3 & 22,9 & 22,9 & 22,8 & 25,4 & 23,2 & 4,2 & & \\
L4 & 23,7 & 24,1 & & 27,1 & 26,7 & 4,0 & 4,1 & \\
L5 & 24,1 & 24,1 & 24,3 & 25,6 & 25,1 & & 4,0 & \\
L6 & 21,2 & 21,2 & 21,0 & 25,8 & 25,2 & 4,4 & & 4,2 \\
\hline X & 23,23 & 23,13 & 22,94 & 26,03 & 25,28 & 4,18 & 4,00 & 4,23 \\
STD & 1,10 & 1,08 & 1,25 & 0,62 & 1,19 & 0,15 & 0,10 & 0,35 \\
CV8 & 4,71 & 4,66 & 5,43 & 2,39 & 4,70 & 3,55 & 2,50 & 8,30 \\
\hline
\end{tabular}


Material: Mistura de grânulos

\begin{tabular}{|c|c|c|c|c|c|c|c|c|}
\hline \multirow{2}{*}{$\begin{array}{l}\text { amost } \\
\text { 09 } \\
\text { labor }\end{array}$} & \multicolumn{3}{|l|}{$8 N$} & \multicolumn{2}{|c|}{$\begin{array}{c}{ }_{8}^{8} \mathrm{P}_{2} \mathrm{O}_{5} \\
\text { cnatagua }\end{array}$} & \multicolumn{3}{|l|}{$8 \mathrm{~K}_{2} \mathrm{O}$} \\
\hline & salic & Raney & simpl & ofic. & simpl & TFBS & $\begin{array}{l}\text { Fot. } \\
\text { chama }\end{array}$ & simpl \\
\hline L1 & 31,4 & 31,6 & 31,5 & 2,1 & 2,2 & 8,1 & & \\
\hline L 2 & 31,1 & 31,4 & 31,1 & 2,2 & 2,0 & 7,7 & 7,7 & 7,0 \\
\hline L3 & 31,8 & 31,6 & 31,5 & 2,1 & 1,2 & 8,0 & & \\
\hline L 4 & 30,6 & 31,7 & 31,1 & 3,0 & 2,7 & 7,7 & 8,2 & \\
\hline L5 & 30,2 & 30,4 & 30,7 & 2,1 & 2,1 & 8,1 & 7,9 & \\
\hline \multicolumn{9}{|l|}{ L6 } \\
\hline $\mathrm{x}$ & 31,02 & 31,34 & 31,18 & 2,30 & 2,04 & 7,92 & 7,93 & 7,00 \\
\hline STD & 0,63 & 0,54 & 0,34 & 0,39 & 0,54 & 0,21 & 0,25 & \\
\hline CV8 & 2,04 & 1,71 & 1,07 & 17,12 & 26,53 & 2,59 & 3,17 & \\
\hline
\end{tabular}

Material: Mistura de grânulos

\begin{tabular}{|c|c|c|c|c|c|c|c|c|}
\hline \multirow{2}{*}{$\begin{array}{l}\text { amost } \\
10\end{array}$} & \multicolumn{3}{|l|}{$8 \mathrm{~N}$} & \multicolumn{2}{|c|}{$\begin{array}{c}8 \mathrm{P}_{2} \mathrm{O}_{5} \\
\text { cnatagua } \\
\end{array}$} & \multicolumn{3}{|l|}{$8 \mathrm{~K}_{2} \mathrm{O}$} \\
\hline & salic & Raney & simpl & ofic. & simpl & TFBS & $\begin{array}{l}\text { Fot } \\
\text { chama }\end{array}$ & simpl \\
\hline L1 & 13,3 & 13,2 & 13,6 & 7,9 & 7,9 & 30,6 & & 30,4 \\
\hline L 2 & 13,2 & 13,2 & 13,9 & 8,0 & 7,9 & 31,4 & 30,1 & 31,3 \\
\hline L 3 & 13,6 & 13,5 & 13,4 & 8,1 & 8,0 & 31,5 & & \\
\hline L 4 & 13,7 & 13,6 & 13,4 & 8,3 & 8,0 & 29,8 & 30,4 & \\
\hline ᄂ5 & 13,2 & 13,5 & 13,3 & 8,1 & 8,1 & & 30,5 & \\
\hline \multicolumn{9}{|l|}{ L 6} \\
\hline$x$ & 13,40 & 13,36 & 13,52 & 8,08 & 7,98 & 30,83 & 30,30 & 30,85 \\
\hline STD & 0,24 & 0,18 & 0,24 & 0,15 & 0,09 & 0,79 & 0,21 & 0,64 \\
\hline CV 8 & 1,75 & 1,36 & 1,77 & 1,84 & 1,05 & 2,57 & 0,69 & 2,06 \\
\hline
\end{tabular}


Material: Mistura de grânulos

\begin{tabular}{|c|c|c|c|c|c|c|c|c|}
\hline \multirow{2}{*}{$\frac{\begin{array}{c}\text { amost } \\
11\end{array}}{\text { labor }}$} & \multicolumn{3}{|l|}{$8 \mathrm{~N}$} & \multicolumn{2}{|c|}{$\begin{array}{c}{ }_{8} \mathrm{P}_{2} \mathrm{O}_{5} \\
\text { cnatagua }\end{array}$} & \multicolumn{3}{|l|}{$8 \mathrm{~K}_{2} \mathrm{O}$} \\
\hline & salic & Raney & simpl & ofic. & simpl & TFBS & $\begin{array}{l}\text { Fot. } \\
\text { chama }\end{array}$ & simp 1 \\
\hline L1 & 20,4 & 20,1 & 20,1 & 14,2 & 14,1 & 20,1 & & 19,5 \\
\hline L 2 & 20,5 & 20,4 & 20,2 & 14,5 & 14,2 & 19,6 & 19,8 & 19,0 \\
\hline L 3 & 20,5 & 20,1 & 20,1 & 14,6 & & 20,1 & & \\
\hline \multicolumn{9}{|l|}{ L 4} \\
\hline L 5 & 20,0 & 20,1 & 20,1 & 14,5 & 14,0 & & 19,3 & 19,3 \\
\hline L 6 & 19,7 & 19,8 & 19,8 & 14,1 & 14,1 & 20,2 & & 20,0 \\
\hline$x$ & 20,22 & 20,10 & 20,06 & 14,38 & 14,10 & 20,0 & 19,55 & 19,45 \\
\hline STD & 0,36 & 0,21 & 0,15 & 0,22 & 0,08 & 0,27 & 0,35 & 0,42 \\
\hline CV8 & 1,76 & 1,06 & 0,76 & 1,51 & 0,58 & 1,35 & 1,81 & 2,16 \\
\hline
\end{tabular}

Material: Mistura de grânulos

\begin{tabular}{|c|c|c|c|c|c|c|c|c|}
\hline \multirow{2}{*}{$\frac{\begin{array}{l}\text { amost } \\
\text { ra12 }\end{array}}{1 \mathrm{ab} .}$} & \multicolumn{3}{|l|}{$8 \mathrm{~N}$} & \multicolumn{2}{|c|}{ 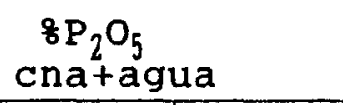 } & \multicolumn{3}{|l|}{$8 \mathrm{~K}_{2} \mathrm{O}$} \\
\hline & salic & Raney & sim & ofic & simpl & TFBS & $\begin{array}{l}\text { Fot. } \\
\text { chama }\end{array}$ & simpl \\
\hline $\mathrm{L} 1$ & 2,4 & 2,3 & 2,3 & 19,4 & 19,4 & 26,6 & & 26,9 \\
\hline $\mathrm{L} 2$ & 2,3 & 2,2 & 2,0 & 19,4 & 18,7 & 26,8 & 27,0 & 27,6 \\
\hline L3 & 2,5 & 2,6 & 2,3 & 19,4 & & 27,1 & & \\
\hline L 4 & 2,1 & 2,2 & & 19,5 & 19,3 & 26,6 & 27,0 & \\
\hline L5 & 2,2 & 2,1 & 2,2 & 19,0 & 19,0 & & 27,5 & \\
\hline \multicolumn{9}{|l|}{ L 6} \\
\hline$x$ & 2,31 & 2,28 & 2,21 & 19,34 & 19,10 & 26,78 & 27,16 & 27,25 \\
\hline STD & 0,16 & 0,21 & 0,15 & 0,20 & 0,32 & 0,24 & 0,29 & 0,49 \\
\hline CV8 & 7,06 & 8,97 & 6,75 & 1,01 & 1,66 & 0,89 & 1,06 & 1,82 \\
\hline
\end{tabular}


Material: Mistura de grânulos

\begin{tabular}{|c|c|c|c|c|c|c|c|c|}
\hline \multirow{2}{*}{$\frac{\begin{array}{c}\text { amos } \\
13\end{array}}{\text { labor }}$} & \multicolumn{3}{|l|}{$\frac{O}{\partial} N$} & \multicolumn{2}{|c|}{$\begin{array}{c}{ }_{8} \mathrm{P}_{2} \mathrm{O}_{5} \\
\text { cnatagua } \\
\end{array}$} & \multicolumn{3}{|l|}{$8 \mathrm{~K}_{2} \mathrm{O}$} \\
\hline & salic & Raney & simpl & ofic. & simpl & TFBS & $\begin{array}{l}\text { Fot. } \\
\text { chama }\end{array}$ & simpl \\
\hline L1 & 12,1 & 11,7 & 11,6 & 5,9 & 6,1 & 11,6 & & 10,6 \\
\hline $\mathrm{L} 2$ & 11,7 & 11,6 & 11,2 & 5,6 & 5,4 & 11,6 & 11,8 & 11,6 \\
\hline L 3 & 11,7 & 11,6 & 11,3 & 5,9 & & 11,6 & & \\
\hline L 4 & 11,7 & 11,7 & 11,2 & 6,3 & 6,1 & 11,7 & 12,0 & \\
\hline ᄂ 5 & 11,8 & 12,0 & 11,9 & 5,7 & 5,8 & & 11,7 & 11,6 \\
\hline \multicolumn{9}{|l|}{$\mathrm{L} 6$} \\
\hline$x$ & 11,80 & 11,72 & 11,44 & 5,88 & 5,85 & 11,63 & 11,83 & 11,27 \\
\hline STD & 0,17 & 0,16 & 0,31 & 0,76 & 0,33 & 0,05 & 0,15 & 0,58 \\
\hline CV용 & 1,47 & 1,40 & 2,67 & 4,66 & 5,67 & 0,43 & 1,29 & 5,12 \\
\hline
\end{tabular}

Material: Mistura de grânulos

\begin{tabular}{|c|c|c|c|c|c|c|c|c|}
\hline \multirow{2}{*}{$\frac{\begin{array}{c}\text { amost } \\
14\end{array}}{1 \text { abor }}$} & \multicolumn{3}{|l|}{$8 \mathrm{~N}$} & \multicolumn{2}{|c|}{$\begin{array}{c}8 \mathrm{P}_{2} \mathrm{O}_{5} \\
\text { cnatagua }\end{array}$} & \multicolumn{3}{|l|}{$8 \mathrm{~K}_{2} \mathrm{O}$} \\
\hline & salic & Raney & simpl & ofic. & simpl & TFBS & $\begin{array}{l}\text { Fot } \\
\text { chama }\end{array}$ & simpl \\
\hline L1 & 5,2 & 5,7 & 5,0 & 23,9 & 23,9 & 26,1 & & 26,6 \\
\hline $\mathrm{L} 2$ & 5,1 & 5,0 & 5,3 & 23,9 & 23,8 & 25,9 & 25,6 & 25,6 \\
\hline L 3 & 5,6 & 5,5 & 5,3 & 24,5 & & 26,7 & & \\
\hline L 4 & 5,3 & 5,3 & 5,1 & 24,5 & 24,3 & 25,3 & 25,5 & \\
\hline L 5 & 5,0 & $5 ; 1$ & 5,0 & 23,7 & 23,3 & & 24,8 & 24,8 \\
\hline \multicolumn{9}{|l|}{ L. 6} \\
\hline$x$ & 5,24 & 5,32 & 5,14 & 24,00 & 23,83 & 26,00 & 25,30 & 25,67 \\
\hline STD & 0,23 & 0,29 & 0,15 & 0,35 & 0,41 & 0,58 & 0,44 & 0,90 \\
\hline $\mathrm{CV} 8$ & 4,39 & 5,38 & 2,95 & 1,44 & 1,73 & 2,22 & 1,72 & 3,51 \\
\hline
\end{tabular}


Material: Mistura de grânulos

\begin{tabular}{|c|c|c|c|c|c|c|c|c|}
\hline \multirow{2}{*}{$\frac{15}{\text { amost }}$} & \multicolumn{3}{|l|}{$8 \mathrm{~N}$} & \multicolumn{2}{|c|}{$\begin{array}{c}8 \mathrm{P}_{2} \mathrm{O}_{5} \\
\text { cnatagua }\end{array}$} & \multicolumn{3}{|l|}{$8 \mathrm{~K}_{2} \mathrm{O}$} \\
\hline & salic & Raney & simpl & ofic. & simpl & TFBS & $\begin{array}{l}\text { Fot } \\
\text { chama }\end{array}$ & simpl \\
\hline L1 & 2,5 & 2,2 & 2,2 & 19,3 & 19,4 & 16,5 & & 16,3 \\
\hline I 2 & 2,1 & 2,0 & 1,9 & 19,1 & 19,1 & 17,0 & 17,1 & 16,2 \\
\hline L 3 & 2,5 & 2,4 & 2,1 & 19,6 & & 17,1 & & \\
\hline L 4 & 2,4 & 2,3 & 2,3 & 19,5 & 20,0 & 16,7 & & 16,8 \\
\hline L 5 & 2,1 & 2,2 & 2,2 & 19,4 & 19,3 & & 16,7 & 16,6 \\
\hline \multicolumn{9}{|l|}{ L6 } \\
\hline$x$ & 2,30 & 2,22 & 2,15 & 19,38 & 19,45 & 16,83 & 16,90 & 16,48 \\
\hline STD & 0,20 & 0,13 & 0,16 & 0,19 & 0,39 & 0,28 & 0,29 & 0,28 \\
\hline CV용 & 8,50 & 6,01 & 7,63 & 0,99 & 1,99 & 1,64 & 1,67 & 1,67 \\
\hline
\end{tabular}

Material: Mistura de grânulos

\begin{tabular}{|c|c|c|c|c|c|c|c|c|}
\hline \multirow{2}{*}{$\frac{\begin{array}{c}\text { amost } \\
16\end{array}}{1 \text { abor }}$} & \multicolumn{3}{|l|}{$8 \mathrm{~N}$} & \multicolumn{2}{|c|}{$\begin{array}{c}{ }^{8} \mathrm{P}_{2} \mathrm{O}_{5} \\
\text { cnatagua }\end{array}$} & \multicolumn{3}{|l|}{$8 \mathrm{~K}_{2} \mathrm{O}$} \\
\hline & salic & Raney & simpl & ofic. & simpl & TFBS & $\begin{array}{l}\text { Fot. } \\
\text { chama }\end{array}$ & simpl \\
\hline L1 & 30,4 & 30,4 & 30,5 & 2,3 & 2,4 & 7,8 & & 5,3 \\
\hline L 2 & 31,6 & 31,2 & 31,2 & 2,0 & & 7,5 & 7,3 & 7,0 \\
\hline L 3 & 32,0 & 31,9 & & 2,0 & & 8,0 & & \\
\hline L 4 & 31,3 & 31,9 & & 2,5 & & 7,5 & 7,8 & \\
\hline ᄃ 5 & 31,1 & 31,0 & 31,2 & 2,4 & & & 7,9 & 8,0 \\
\hline L6 & & & & & & & & \\
\hline$x$ & 31,28 & 31,28 & 30,97 & 2,24 & 2,4 & 7,70 & 7,67 & 6,77 \\
\hline STD & 0,60 & 0,64 & 0,40 & 0,23 & & 0,25 & 0,32 & 1,37 \\
\hline CV8 & 1,91 & 2,04 & 1,31 & 10,29 & & 3,18 & 4,19 & 20,17 \\
\hline
\end{tabular}


Material: Mistura de grânulos

\begin{tabular}{|c|c|c|c|c|c|c|c|c|}
\hline \multirow{2}{*}{ amost } & \multicolumn{3}{|l|}{$8 N$} & \multicolumn{2}{|l|}{$8 \mathrm{P}_{2} \mathrm{O}_{5}$} & \multicolumn{3}{|l|}{$8 \mathrm{~K}_{2} \mathrm{O}$} \\
\hline & salic & Raney & simpl & ofic. & simpl & TFBS & $\begin{array}{l}\text { Fot. } \\
\text { chama }\end{array}$ & simpl \\
\hline L1 & 20,0 & 20,3 & & 12,8 & 13,5 & 1,7 & & 1,8 \\
\hline L 2 & 21,2 & 20,7 & 21,3 & 12,7 & 12,4 & 1,9 & 1,7 & 1,9 \\
\hline L 3 & 20,6 & 20,3 & 20,3 & 13,0 & & 2,1 & & \\
\hline L 4 & 20,7 & 20,5 & & 13,2 & 13,4 & 1,8 & 1,6 & \\
\hline Ł 5 & 21,3 & 20,4 & 20,8 & 12,8 & 12,9 & & 1,7 & 1,7 \\
\hline \multicolumn{9}{|l|}{ L6 } \\
\hline$x$ & 20,76 & 20,44 & 20,80 & 12,90 & 13,05 & 1,88 & 1,65 & 1,81 \\
\hline STD & 0,52 & 0,17 & 0,50 & 0,20 & 0,51 & 0,17 & 0,05 & 0,10 \\
\hline $\mathrm{CV} 8$ & 2,52 & 0,82 & 2,40 & 1,55 & 3,88 & 9,02 & 2,73 & 5,61 \\
\hline
\end{tabular}

Material: Fosfato Diamônico

\begin{tabular}{|c|c|c|c|c|c|c|c|}
\hline$\underset{04}{\operatorname{amost}}$ & \multicolumn{3}{|c|}{$8 \mathrm{~N}$ total } & \multicolumn{2}{|c|}{${ }_{8}^{8} \mathrm{P}_{2} \mathrm{O}_{5} \quad$ água } & \multicolumn{2}{|c|}{$\underset{\text { gua }}{\stackrel{8}{8} \mathrm{P}_{2} \mathrm{O}_{5}}$ cnatá- } \\
\hline $1 \mathrm{ab}$. & salic & Raney & simp & ofic. & simp. & ofic. & simp. \\
\hline L1 & 20,5 & 21,2 & 18,2 & 39,9 & & 42,4 & 42,9 \\
\hline L 2 & 17,6 & 17,4 & 17,4 & 39,6 & 44,1 & 39,9 & 44,5 \\
\hline L 3 & 17,5 & & 17,3 & 39,1 & 44,7 & & 44,4 \\
\hline L 4 & 17,2 & 17,5 & 17,3 & 40,1 & 43,9 & 40,0 & 44,3 \\
\hline L5 & 17,8 & 17,6 & 18,2 & 39,8 & 44,0 & & 44,1 \\
\hline L6 & 17,7 & 17,8 & 17,4 & 39,7 & 39,8 & 44,3 & 44,8 \\
\hline $\mathrm{X}$ & 18,05 & 18,30 & 17,63 & 39,70 & 43,30 & 41,65 & 44,17 \\
\hline STD & 1,22 & 1,63 & 0,44 & 0,34 & 1,98 & 2,11 & 0,66 \\
\hline $\mathrm{CV} 8$ & 6,75 & 8,90 & 2,50 & 0,86 & 4,58 & 5,07 & 1,50 \\
\hline
\end{tabular}


Material: Superfosfato Simples

\begin{tabular}{|l|l|l|l|l|l|l|}
\hline $\begin{array}{l}\text { amost. } \\
13\end{array}$ & \multicolumn{2}{|l|}{$8 \mathrm{P}_{2} \mathrm{O}_{5}$ água } & \multicolumn{2}{l|}{$8 \mathrm{P}_{2} \mathrm{O}_{5}$ cnatágua } & \multicolumn{2}{l|}{$8 \mathrm{P}_{2} \mathrm{O}_{5}$ total } \\
\hline lab. & ofic. & simpl. & ofic. & simp. & ofic. & simpl. \\
\hline L1 & 14,9 & & 19,2 & 18,8 & 20,9 & \\
L2 & 15,3 & 15,5 & 18,7 & 17,5 & 21,0 & 20,6 \\
L3 & 15,9 & & 19,0 & & & \\
L4 & 15,7 & 16,1 & 19,2 & 18,6 & & 22,2 \\
L5 & 15,4 & 15,4 & 19,1 & 16,9 & 21,0 & 20,9 \\
L6 & & & & & & \\
\hline média & 15,44 & 15,67 & 19,04 & 17,95 & 20,97 & 21,23 \\
STD & 0,38 & 0,38 & 0,21 & 0,90 & 0,58 & 0,85 \\
CV8 & 2,49 & 2,42 & 1,09 & 5,03 & 0,28 & 4,00 \\
\hline
\end{tabular}

Material: Superfosfato Triplo

\begin{tabular}{|l|l|l|l|l|l|l|}
\hline $\begin{array}{l}\text { amost. } \\
\text { O2 }\end{array}$ & \multicolumn{2}{|l|}{$8 \mathrm{P}_{2} \mathrm{O}_{5}$ água } & \multicolumn{2}{l|}{$8 \mathrm{P}_{2} \mathrm{O}_{5}$ cnatágua } & \multicolumn{2}{l|}{$8 \mathrm{P}_{2} \mathrm{O}_{5}$ total } \\
\hline lab. & ofic. & simpl. & ofic. & simp. & ofic. & simpl. \\
\hline L1 & 39,6 & & 445,8 & 45,7 \\
L2 & 40,8 & 41,0 & 45,0 & 44,6 & 46,0 & 45,2 \\
L3 & 40,2 & 40,7 & 46,0 & 46,0 & & \\
L4 & 40,7 & 40,7 & 46,7 & 46,1 & 46,6 & 46,5 \\
L5 & 40,4 & & 46,2 & 46,3 & 45,9 & \\
L6 & 39,8 & 40,0 & 45,4 & 45,4 & 45,6 & 45,8 \\
\hline X & 40,25 & 40,60 & 45,85 & 45,68 & 45,96 & 45,83 \\
STD & 0,48 & 0,42 & 0,60 & 0,69 & 0,39 & 0,65 \\
CV8 & 1,19 & 1,04 & 1,31 & 1,51 & 0,85 & 1,42 \\
\hline
\end{tabular}


Material: Superfosfato simples

\begin{tabular}{|c|c|c|c|c|c|c|}
\hline amost & \multicolumn{2}{|c|}{${ }^{\circ} \mathrm{P}_{2} \mathrm{O}_{5}$ água } & \multicolumn{2}{|c|}{${ }_{8} \mathrm{P}_{2} \mathrm{O}_{5} \mathrm{cna}+a ́ g u a$} & \multicolumn{2}{|c|}{$8 \mathrm{P}_{2} \mathrm{O}_{5}$ total } \\
\hline $1 \mathrm{ab}$. & of ic. & simpl. & ofic. & simp. & of ic. & simpl. \\
\hline L1 & 17,0 & & 19,0 & 19,4 & 18,9 & \\
\hline ᄂ2 & 17,9 & 17,9 & 18,9 & 19,2 & 19,0 & 19,3 \\
\hline L 3 & 17,6 & & 19,4 & & 19,2 & \\
\hline L 4 & 18,1 & 17,7 & 19,7 & 19,4 & & 19,6 \\
\hline L 5 & 17,7 & 17,5 & 19,4 & 19,3 & 19,3 & \\
\hline L 6 & 17,4 & 17,0 & 19,1 & 18,9 & 19,4 & 19,2 \\
\hline $\mathrm{X}$ & 17,62 & 17,53 & 19,25 & 19,24 & 19,16 & 19,37 \\
\hline STD & 0,39 & 0,39 & 0,30 & 0,21 & 0,21 & 0,21 \\
\hline $\mathrm{CV}$ 웅 & 2,20 & 2,20 & 1,57 & 1,08 & 1,08 & 1,08 \\
\hline
\end{tabular}

Material: Superfosfato Simples

\begin{tabular}{|l|l|l|l|l|l|l|}
\hline $\begin{array}{l}\text { amost. } \\
08\end{array}$ & \multicolumn{2}{|l|}{$8 \mathrm{P}_{2} \mathrm{O}_{5}$ água } & \multicolumn{2}{|l|}{$8 \mathrm{P}_{2} \mathrm{O}_{5}$ cnatágua } & \multicolumn{2}{l}{$8 \mathrm{P}_{2} \mathrm{O}_{5}$ total } \\
\hline lab. & of ic & simpl & of ic & simp & of ic & simpl \\
\hline L1 & 17,7 & & 19,5 & 19,6 & 19,6 & \\
L2 & 17,8 & 17,2 & 19,4 & 19,0 & 19,4 & 19,0 \\
L3 & 17,2 & 17,1 & 19,5 & 18,5 & 19,5 & 18,5 \\
L4 & 17,3 & 17,9 & 20,6 & 20,3 & & 20,0 \\
L5 & 17,5 & 18,1 & 19,6 & 20,0 & 19,6 & 19,6 \\
L6 & 17,6 & 17,5 & 19,2 & 19,1 & 19,3 & 19,2 \\
\hline X & 17,52 & 17,56 & 19,63 & 19,42 & 19,48 & 19,26 \\
STD & 0,23 & 0,43 & 0,49 & 0,67 & 0,13 & 0,57 \\
CV8 & 1,32 & 2,47 & 2,51 & 3,47 & 0,67 & 2,97 \\
\hline
\end{tabular}


Material: Fosfato Natural Parcialmente Acidulado

\begin{tabular}{|c|c|c|c|c|}
\hline amostra 12 & $8_{8} \mathrm{P}_{2} \mathrm{O}_{5}$ água & \multicolumn{2}{c|}{$8 \mathrm{P}_{2} \mathrm{O}_{5}$ cna+água } \\
\hline laboratório & oficial & simplific. & oficial & simplific. \\
\hline L1 & 1,2 & & 8,0 & 7,7 \\
L2 & 1,1 & 1,1 & 8,1 & 7,9 \\
L3 & 1,3 & & 8,2 & \\
L4 & 1,2 & 1,7 & 7,6 & 8,4 \\
L5 & 1,3 & 1,4 & 7,8 & 8,1 \\
L6 & 1,21 & 1,40 & & \\
\hline X & 0,09 & 0,30 & 7,94 & 8,03 \\
STD & 7,12 & 21,43 & 0,24 & 0,30 \\
CV8 & & & 3,03 & 3,72 \\
\hline
\end{tabular}

Material: Fosfato Natural Parcialmente Acidulado

\begin{tabular}{|c|c|c|c|c|}
\hline amostra 17 & \multicolumn{2}{|c|}{$8 \mathrm{P}_{2} \mathrm{O}_{5}$ água } & \multicolumn{2}{c|}{$8 \mathrm{P}_{2} \mathrm{O}_{5}$ cna água } \\
\hline laboratório & oficial & simplific & oficial & simplific. \\
\hline L1 & 1,6 & & 8,5 & 8,0 \\
L2 & 1,2 & 1,5 & 7,9 & 8,3 \\
L3 & 1,4 & & 8,4 & \\
L4 & 1,8 & 2,0 & 8,1 & 8,5 \\
L5 & 1,4 & 1,4 & 7,9 & 8,2 \\
L6 & 1,48 & 1,64 & & \\
\hline X & 0,24 & 0,35 & 8,16 & 8,25 \\
STD & 16,05 & 21,45 & 0,28 & 0,21 \\
CV8 & & & 3,42 & 2,52 \\
\hline
\end{tabular}


Material: Superfosfato Triplo

\begin{tabular}{|l|l|l|l|l|l|l|}
\hline $\begin{array}{l}\text { amost. } \\
10\end{array}$ & \multicolumn{2}{|l|}{$8 \mathrm{P}_{2} \mathrm{O}_{5}$ água } & \multicolumn{2}{l|}{$8 \mathrm{P}_{2} \mathrm{O}_{5}$ cnatágua } & \multicolumn{2}{l|}{$8 \mathrm{P}_{2} \mathrm{O}_{5}$ total } \\
\hline lab. & ofic. & simpl. & of ic. & simp. & of ic. & simpl. \\
\hline L1 & 40,3 & & 46,0 & 46,1 & 46,1 & \\
L2 & 40,2 & 40,9 & 45,5 & 45,3 & 45,4 & 45,7 \\
L3 & 40,1 & 39,8 & 45,4 & 45,0 & 46,0 & \\
L4 & 40,7 & 40,8 & 46,7 & 46,7 & & 46,4 \\
L5 & 39,9 & 40,2 & 46,2 & 46,5 & 46,3 & 46,3 \\
L6 & 40,2 & 40,3 & 45,7 & 45,7 & 45,8 & 45,7 \\
\hline X & 40,23 & 40,40 & 45,92 & 45,88 & 45,92 & 46,03 \\
STD & 0,27 & 0,45 & 0,49 & 0,67 & 0,34 & 0,38 \\
CV8 & 0,66 & 1,12 & 1,06 & 1,46 & 0,75 & 0,82 \\
\hline
\end{tabular}

Material: Fosfato Natural Parcialmente Acidulado

\begin{tabular}{|c|c|c|c|c|}
\hline amostra 01 & \multicolumn{2}{|c|}{$8 \mathrm{P}_{2} \mathrm{O}_{5}$ água } & \multicolumn{2}{c|}{$8 \mathrm{P}_{2} \mathrm{O}_{5}$ cna+água } \\
\hline laboratório & oficial & simplif. & oficial & simplif. \\
\hline L1 & 1,2 & 8,3 & 8,9 \\
L2 & 1,4 & 1,5 & 8,1 & 8,1 \\
L3 & 1,6 & 1,5 & 8,2 & \\
L4 & 1,3 & & & \\
L5 & 1,2 & 1,1 & 8,4 & 8,3 \\
L6 & 1,34 & 1,36 & 8,20 & 8,40 \\
X & 0,17 & 0,23 & 0,16 & 0,35 \\
STD & 12,67 & 16,57 & 1,93 & 4,12 \\
CV8 & & & & 8,0 \\
\hline
\end{tabular}


Material: Cloreto de Potássio

\begin{tabular}{|c|c|c|c|}
\hline amostra 06 & \multicolumn{3}{|c|}{$8 \mathrm{~K}_{2} \mathrm{O}$} \\
\hline laboratório & TFBS & fot.chama & simplificado \\
\hline L1 & 60,8 & 60,2 \\
L2 & 60,8 & 60,9 & 60,9 \\
L3 & 62,5 & & \\
L4 & 59,7 & 60,3 & 60,2 \\
L5 & & 59,4 & 59,4 \\
L6 & 60,5 & & 60,7 \\
\hline X & 60,86 & 60,20 & 60,28 \\
STD & 1,02 & 0,76 & 0,58 \\
CV8 & 1,67 & 1,25 & 0,96 \\
\hline
\end{tabular}

Material: Cloreto de Potássio

\begin{tabular}{|c|c|c|c|}
\hline amostra 9 & \multicolumn{3}{|c|}{$8 \mathrm{~K}_{2} \mathrm{O}$} \\
\hline laborat6rio & TFBS & fot.chama & simplificado \\
\hline L1 & 60,0 & & 60,3 \\
L2 & 58,1 & 58,2 & 58,5 \\
L3 & 60,5 & & \\
L4 & 60,6 & 60,6 & \\
L5 & 60,0 & 60,2 & \\
L6 & &. & 59,40 \\
X & 59,84 & 59,67 & 1,27 \\
STD & 1,01 & 1,29 & 2,14 \\
CV8 & 1,69 & 2,16 & \\
\hline
\end{tabular}


Material: Fosfato Diamônico

\begin{tabular}{|c|c|c|c|c|c|c|c|}
\hline \multirow{2}{*}{$\begin{array}{c}\begin{array}{c}\text { amost } \\
11\end{array} \\
\text { labor }\end{array}$} & \multicolumn{3}{|c|}{ of total } & \multicolumn{2}{|c|}{${ }_{8}^{8} \mathrm{P}_{2} \mathrm{O}_{5}$ água } & \multicolumn{2}{|c|}{$\begin{array}{l}{ }_{8 \mathrm{P}_{2}} \mathrm{O}_{5} \text { cnata- } \\
\text { gua }\end{array}$} \\
\hline & salic & Raney & simpl. & of ic. & simpl. & ofic. & simpl. \\
\hline L1 & 17,6 & 17,4 & 17,1 & 39,3 & & 44,1 & 43,9 \\
\hline L2 & 18,2 & 18,7 & 17,1 & 39,3 & 38,3 & 44,0 & 43,7 \\
\hline L3 & 17,6 & 17,4 & 17,1 & 39,5 & & 44,2 & \\
\hline \multicolumn{8}{|l|}{ L 4} \\
\hline L5 & 17,5 & 17,6 & 17,3 & 40,3 & 40,3 & 44,5 & 44,0 \\
\hline L6 & 17,4 & 17,5 & 17,1 & 38,2 & 38,0 & 46,0 & 45,7 \\
\hline$x$ & 17,66 & 17,72 & 17,14 & 39,32 & 38,87 & 44,56 & 44,33 \\
\hline STD & 0,31 & 0,55 & 0,09 & 0,75 & 1,25 & 0,83 & 0,93 \\
\hline $\mathrm{CV} 8$ & 1,77 & 3,12 & 0,52 & 1,91 & 3,22 & 1,85 & 2,09 \\
\hline
\end{tabular}

Material: Fosfato Diamônico

\begin{tabular}{|c|c|c|c|c|c|c|c|}
\hline$\underset{16}{\operatorname{amost}}$ & \multicolumn{3}{|c|}{ of total } & \multicolumn{2}{|c|}{${ }_{8} \mathrm{P}_{2} \mathrm{O}_{5}$ água } & \multicolumn{2}{|c|}{$\underset{g u a}{\stackrel{8}{8} \mathrm{P}_{2} \mathrm{O}_{5} \text { cnatá- }}$} \\
\hline labor & salic. & Raney & simpl. & ofic. & simpl. & ofic. & simpl. \\
\hline L1 & 17,0 & 17,4 & 17,2 & 37,8 & & 46,1 & 46,0 \\
\hline $\mathrm{L} 2$ & 17,4 & 17,2 & 17,1 & 37,3 & 36,0 & 45,1 & 45,3 \\
\hline L 3 & 16,5 & 16,4 & 16,2 & 40,0 & & 45,8 & \\
\hline L 4 & 16,6 & 16,7 & 16,2 & 39,4 & 38,5 & 48,5 & 45,7 \\
\hline L 5 & 17,0 & 17,1 & 17,1 & 38,6 & 38,5 & 45,7 & 45,5 \\
\hline \multicolumn{8}{|l|}{ L6 } \\
\hline $\mathrm{x}$ & 16,90 & 16,96 & 16,76 & 38,62 & 37,67 & 46,24 & 45,88 \\
\hline STD & 0,36 & 0,40 & 0,51 & 1,11 & 1,44 & 1,31 & 0,62 \\
\hline $\mathrm{CV}$ 용 & 2,13 & 2,38 & 3,06 & 2,87 & 3,83 & 2,84 & 1,36 \\
\hline
\end{tabular}


Material: Termofosfato

\begin{tabular}{|c|c|c|}
\hline amostra 3 & $8 \mathrm{P}_{2} \mathrm{O}_{5}$ total \\
\hline laboratório & Oficial & simplificado \\
\hline L1 & 28,4 & \\
L2 & 28,3 & 28,4 \\
L3 & 28,4 & 28,2 \\
L4 & & 28,0 \\
L5 & 28,0 & \\
L6 & & \\
X & 28,28 & 28,20 \\
STD & 0,35 & 0,20 \\
CV8 & 1,32 & 0,59 \\
\hline
\end{tabular}

Material: Termofosfato

\begin{tabular}{|c|c|c|}
\hline amostra 03 & \multicolumn{2}{|c|}{ of $\mathrm{P}_{2} \mathrm{O}_{5}$ Total } \\
\hline Laboratório & Oficial & Simplificado \\
\hline L1 & 27,7 & 28,6 \\
L2 & 28,7 & 28,3 \\
L3 & 28,4 & \\
L4 & 28,0 & \\
L5 & 28,6 & 28,6 \\
L6 & 28,4 & 28,50 \\
X & 28,30 & 0,17 \\
STD & 0,38 & 0,61 \\
CV8 & 1,34 & \\
\hline
\end{tabular}


Material: Uréia

\begin{tabular}{|c|c|c|c|}
\hline amostra 14 & \multicolumn{3}{c|}{ 8N total } \\
\hline laboratório & Salicilico & Liga Raney & Simplificado \\
\hline L1 & 45,1 & 45,4 & 45,3 \\
L2 & 45,6 & 45,7 & 45,3 \\
L3 & 45,3 & 45,1 & \\
L4 & 46,5 & 46,2 & 46,1 \\
L5 & 45,0 & 45,2 & 44,9 \\
L6 & & & 45,40 \\
X & 45,50 & 45,52 & 0,50 \\
STD & 0,60 & 0,44 & 1,11 \\
CV8 & 1,33 & 0,98 & \\
\hline
\end{tabular}

Material: Nitrato de Amônio

\begin{tabular}{|c|c|c|c|}
\hline amostra 15 & \multicolumn{3}{c|}{ 8 N total } \\
\hline laboratório & Salicílico & Liga Raney & Simplificado \\
\hline L1 & 33,5 & 33,3 & 33,7 \\
L2 & 33,7 & 33,4 & 32,1 \\
L3 & 33,7 & 33,5 & \\
L4 & 31,9 & 32,4 & 33,7 \\
L5 & 34,0 & 34,1 & 34,1 \\
L6 & & & \\
\hline X & 33,36 & 33,34 & 33,40 \\
STD & 0,84 & 0,61 & 0,89 \\
CV8 & 2,50 & 1,83 & 2,66 \\
\hline
\end{tabular}


Resultados do estudo de composição de variância das determinaçōes de nitrogênio, fósforo e potássio

\begin{tabular}{|c|c|c|c|c|c|c|}
\hline \multirow[t]{2}{*}{ amostra } & \multicolumn{2}{|c|}{$8 \mathrm{~N}$ total } & \multicolumn{2}{|c|}{$8 \mathrm{P}_{2} \mathrm{O}_{5}$ cna $\mathrm{c}$ água } & \multicolumn{2}{|l|}{$8 \mathrm{~K}_{2} \mathrm{O}$} \\
\hline & repet, 1 & repet, 2 & repet, 1 & repet, 2 & repet, 1 & repet, 2 \\
\hline A-01 & 3,95 & 4,06 & 13,40 & 13,40 & 8,05 & 8,40 \\
\hline A-02 & 3,92 & 4,03 & 13,10 & 13,20 & 8,50 & 8,30 \\
\hline A-03 & 3,95 & 4,12 & 13,30 & 13,20 & 7,95 & 7,80 \\
\hline $\mathrm{A}-04$ & 3,86 & 3,94 & 13,40 & 13,20 & 8,30 & 8,10 \\
\hline A-05 & 3,89 & 4,09 & 13,10 & 13,20 & 8,60 & 8,40 \\
\hline A-06 & 4,00 & 4,03 & 13,10 & 13,20 & 8,20 & 8,15 \\
\hline A-07 & 3,92 & 3,97 & 13,10 & 12,90 & 8,95 & 8,90 \\
\hline$A-08$ & 3,95 & 3,82 & 13,20 & 12,80 & 9,35 & 8,80 \\
\hline $\mathrm{B}-01$ & 3,62 & 3,64 & 13,50 & 13,20 & 8,50 & 8,20 \\
\hline B-02 & 3,86 & 3,88 & 13,30 & 13,10 & 8,55 & 8,30 \\
\hline $\mathrm{B}-03$ & 3,77 & 3,88 & 13,60 & 13,50 & 8,25 & 7,90 \\
\hline B-04 & 3,77 & 3,67 & 13,40 & 13,40 & 8,45 & 8,03 \\
\hline B-05 & 3,86 & 3,88 & 13,60 & 13,40 & 8,00 & 8,00 \\
\hline B-06 & 3,89 & 3,94 & 13,20 & 13,10 & 7,85 & 7,70 \\
\hline B- 07 & 3,80 & 3,85 & 13,40 & 13,40 & 8,00 & 8,03 \\
\hline B- 08 & 3,89 & 3,88 & 13,40 & 13,30 & 7,70 & 7,60 \\
\hline $\mathrm{C}-01$ & 3,89 & 3,90 & 13,30 & 13,40 & 8,20 & 8,20 \\
\hline $\mathrm{C}-02$ & 4,07 & 4,18 & 13,20 & 13,30 & 8,45 & 7,92 \\
\hline $\mathrm{C}-03$ & 3,71 & 4,12 & 13,20 & 13,30 & 8,85 & 8,10 \\
\hline $\mathrm{C}-04$ & 4,04 & 4,09 & 13,30 & 13,40 & 8,60 & 8,02 \\
\hline $\mathrm{C}-05$ & 3,86 & 4,09 & 13,20 & 13,20 & 8,60 & 8,20 \\
\hline$C-06$ & 4,01 & 4,03 & 13,40 & 13,10 & 8,60 & 8,00 \\
\hline $\mathrm{C}-07$ & 3,71 & 4,03 & 13,40 & 13,20 & 8,40 & 8,28 \\
\hline C-08 & 4,10 & 4,12 & 13,40 & 13,10 & 8,30 & 8,09 \\
\hline
\end{tabular}


Resultados do estudo de composição de variância das determinaçōes de nitrogênio, fósforo e potássio

\begin{tabular}{|c|c|c|c|c|c|c|}
\hline \multirow[t]{2}{*}{ amostra } & \multicolumn{2}{|l|}{$8 \mathrm{~N}$ total } & \multicolumn{2}{|c|}{$8 \mathrm{P}_{2} \mathrm{O}_{5}$ cnatágua } & \multicolumn{2}{|l|}{$8 \mathrm{~K}_{2} \mathrm{O}$} \\
\hline & repet, 1 & repet, 2 & repet, 1 & repet, 2 & repet, 1 & repet, 2 \\
\hline$D-01$ & 3,92 & 3,88 & 13,40 & 13,20 & 8,00 & 8,13 \\
\hline$D-02$ & 3,92 & 3,94 & 13,30 & 13,10 & 8,00 & 8,25 \\
\hline$D-03$ & 4,01 & 3,90 & 13,20 & 13,20 & 8,00 & 8,00 \\
\hline$D-04$ & 3,92 & 4,00 & 13,70 & 13,40 & 8,30 & 8,25 \\
\hline $\mathrm{D}-05$ & 3,95 & 4,12 & 13,20 & 13,10 & 8,40 & 8,20 \\
\hline $\mathrm{D}-06$ & 3,92 & 3,97 & 13,40 & 13,40 & 8,45 & 8,21 \\
\hline $\mathrm{D}-07$ & 4,01 & 4,03 & 13,30 & 13,40 & 8,25 & 8,39 \\
\hline $\mathrm{D}-08$ & 4,01 & 4,06 & 13,30 & 13,30 & 8,25 & 8,35 \\
\hline $\mathbf{E}-01$ & 3,86 & 3,94 & 14,00 & 14,00 & 8,00 & 8,15 \\
\hline $\mathrm{E}-02$ & 3,77 & 3,88 & 13,70 & 13,90 & 8,65 & 9,00 \\
\hline $\mathbf{E}-03$ & 4,10 & 4,12 & 13,70 & 13,90 & 8,10 & 8,40 \\
\hline E-04 & 3,71 & 3,94 & 14,00 & 13,80 & 7,95 & 8,00 \\
\hline$E-05$ & 3,92 & 4,21 & 13,70 & 13,70 & 8,40 & 8,80 \\
\hline E-06 & 3,80 & 4,03 & 13,70 & 13,90 & 8,60 & 8,61 \\
\hline E-07 & 3,70 & 3,76 & 13,80 & 13,70 & 8,05 & 8,20 \\
\hline$E-08$ & 3,70 & 3,79 & 13,70 & 14,20 & 7,80 & 8,05 \\
\hline$F-01$ & 3,88 & 3,90 & 13,10 & 13,40 & 8,00 & 8,25 \\
\hline$F-02$ & 4,00 & 4,06 & 13,10 & 13,40 & 7,50 & 8,00 \\
\hline$F-03$ & 3,88 & 3,97 & 13,10 & 13,40 & 8,06 & 8,30 \\
\hline$F-04$ & 4,12 & 4,06 & 13,10 & 13,20 & 7,80 & 8,05 \\
\hline$F-05$ & 4,00 & 4,03 & 13,30 & 13,20 & 7,30 & 7,65 \\
\hline$F-06$ & 3,88 & 3,90 & 13,40 & 13,40 & 7,80 & 8,00 \\
\hline$F-07$ & 4,18 & 4,18 & 13,00 & 13,00 & 8,10 & 8,25 \\
\hline$F-08$ & 4,15 & 4,12 & 13,00 & 13,10 & 8,50 & 8,50 \\
\hline
\end{tabular}


Porcentagem em peso da amostras de fertilizantes retidos nas peneiras, no ensaio granulométrico.

\begin{tabular}{|c|c|c|c|c|c|}
\hline \multirow{3}{*}{ amostra } & \multicolumn{5}{|c|}{8 de retenção } \\
\hline & \multicolumn{5}{|c|}{ abertura de malha em mm } \\
\hline & $<0,50$ & $0,50-1,19$ & $1,19-2,38$ & $2,38-4,00$ & $>4,00$ \\
\hline A5 & 3,61 & 2,99 & 44,69 & 47,64 & 0,93 \\
\hline A6 & 3,33 & 3,45 & 47,70 & 44,37 & 1,00 \\
\hline A7 & 2,93 & 2,75 & 46,01 & 47,01 & 1,03 \\
\hline A8 & 3,08 & 2,91 & 42,87 & 49,92 & 0,87 \\
\hline $\mathrm{B} 5$ & 2,35 & 2,88 & 46,99 & 47,58 & 0,41 \\
\hline $\mathrm{B} 6$ & 1,56 & 2,39 & 44,83 & 50,39 & 0,45 \\
\hline $\mathrm{B} 7$ & 2,12 & 2,39 & 45,42 & 48,99 & 0,82 \\
\hline $\mathrm{B} 8$ & 2,46 & 2,58 & 46,84 & 47,20 & 0,66 \\
\hline $\mathrm{C5}$ & 3,04 & 3,26 & 46,72 & 46,06 & 0,79 \\
\hline $\mathrm{C6}$ & 3,34 & 2,82 & 44,18 & 48,34 & 1,19 \\
\hline $\mathrm{C7}$ & 2,26 & 2,62 & 42,99 & 50,80 & 1,13 \\
\hline $\mathrm{cs}$ & 3,10 & 3,32 & 45,27 & 47,36 & 0,83 \\
\hline D5 & 2,30 & 3,00 & 47,30 & 46,43 & 0,66 \\
\hline D6 & 2,85 & 2,74 & 44,04 & 49,48 & 0,55 \\
\hline D7 & 3,36 & 2,89 & 47,99 & 44,84 & 0,74 \\
\hline D8 & 2,69 & 2,98 & 45,89 & 47,44 & 0,59 \\
\hline E5 & 2,83 & 3,21 & 45,44 & 47,71 & 0,54 \\
\hline E6 & 2,89 & 3,21 & 44,53 & 48,71 & 0,45 \\
\hline E7 & 2,13 & 1,92 & 40,57 & 53,99 & 1,07 \\
\hline E8 & 2,55 & 3,26 & 49,32 & 43,68 & 0,90 \\
\hline F5 & 2,21 & 2,77 & 49,29 & 44,83 & 0,71 \\
\hline F6 & 1,70 & 2,57 & 49,32 & 45,44 & 0,55 \\
\hline F7 & 1,32 & 2,15 & 45,75 & 49,62 & 0.79 \\
\hline F8 & 1,63 & 2,76 & 48,54 & 45,85 & 0,71 \\
\hline
\end{tabular}




Peso das amostras quarteadas
\begin{tabular}{|l|l|l|l|l|l|l|}
\hline Quarteação & \multicolumn{5}{|c|}{ Amostragem } \\
\hline repetição & A & B & C & D & E & F \\
\hline Q1 & 142,5 & 134,1 & 152,3 & 165,9 & 137,3 & 119,5 \\
\hline Q2 & 148,3 & 134,3 & 156,8 & 170,0 & 144,4 & 122,5 \\
\hline Q3 & 153,3 & 155,1 & 167,5 & 165,3 & 159,9 & 129,8 \\
\hline Q4 & 159,0 & 150,4 & 158,3 & 176,6 & 153,0 & 123,0 \\
\hline Q5 & 141,6 & 134,4 & 158,6 & 164,4 & 147,7 & 132,9 \\
\hline Q6 & 149,3 & 137,1 & 157,1 & 153,1 & 148,7 & 133,9 \\
\hline Q7 & 193,2 & 157,3 & 190,5 & 189,3 & 177,3 & 133,4 \\
\hline Q8 & 197,8 & 156,8 & 196,1 & 193,3 & 155,3 & 139,7 \\
\hline
\end{tabular}

